upf. $\begin{array}{ll}\text { Universitat } \\ \text { Pompeu Fabra } \\ \text { Barcelona }\end{array} \quad \begin{aligned} & \text { Department } \\ & \text { of Economics and Business }\end{aligned}$

Economics Working Paper Series

Working Paper No. 1579

\title{
The effect of horizontal mergers, when firms compete in prices and investments
}

Massimo Motta and Emanuele Tarantino

30 August 2017 


\title{
The Effect of Horizontal Mergers, When Firms Compete in Prices and Investments*
}

\author{
Massimo Motta \\ ICREA-Universitat Pompeu Fabra and Barcelona GSE
}

\author{
Emanuele Tarantino \\ University of Mannheim and $M a C C I$
}

30 August 2017

\begin{abstract}
It has been suggested that mergers, by increasing concentration, raise incentives to invest and hence are pro-competitive. To study the effects of mergers, we rewrite a game with simultaneous price and cost-reducing investment choices as one where firms only choose prices, and make use of aggregative game theory. We find no support for that claim: absent efficiency gains, the merger lowers total investments and consumer surplus. Only if it entails sufficient efficiency gains, will it be pro-competitive. We also show there exist classes of models for which the results obtained with cost-reducing investments are equivalent to those with quality-enhancing investments.
\end{abstract}

JEL classification: K22, D43, L13, L41.

Keywords: horizontal mergers; innovation; investments; network-sharing agreements; competition.

\footnotetext{
${ }^{*}$ We are especially grateful to Bruno Jullien and Nicolas Schutz for insightful discussions and suggestions. This paper also benefited from comments by Benno Buehler, Rosa Ferrer, Emeric Henry, Ángel López, Christian Michel, Jorge Padilla, Álvaro Parra, Michele Polo, Markus Reisinger, Patrick Rey, Fiona Scott Morton, Howard Shelanski, Bert Willems, and the participants in the Hebrew University (Jerusalem) and Northwestern University seminars, and in the CEPR-JIE Conference on Applied Industrial Organization, European Commission Economic Advisory Group on Competition Policy plenary meeting, MaCCI Summer Institute, MaCCI Annual Conference (Mannheim), TILEC Media and Communication Workshop (Tilburg), and CRESSE (Crete). Motta gratefully acknowledges financial support from the Spanish Ministry of Economy and Competitiveness through grant ECO2013-43011-P and the Severo Ochoa Programme for Centres of Excellence in RD (SEV-2015-0563). The usual disclaimer applies. This supersedes a previous version bearing the title "The effect of a merger on investments", published as CEPR Discussion Paper 11550 (2016).
} 


\section{Introduction}

In a series of recent high-profile mergers in the mobile telephony industry in the $\mathrm{EU},{ }^{1}$ the telecom industry has urged the European Commission (which had jurisdiction on these mergers) to take into account that the mergers would have led to higher investments. Mobile Network Operators (MNOs) have made two main arguments in support of this claim. The first is related to existence of scale economies of various nature, and as such it is not conceptually controversial (but it would need to be empirically verified). ${ }^{2}$ The second argues that a merger favors investments because industry consolidation would give firms stronger incentives to invest. This argument in particular has resonated with politicians and heads of government, and has been widely discussed in the press. ${ }^{3}$ Whether mergers encourage or not investment and innovation is an issue which goes well beyond the telecom industry. Antitrust agencies all over the world, for instance, recognize the importance of assessing the dynamic effects of a merger and the possibility that it may reduce innovation and product variety. ${ }^{4}$

To our knowledge, and quite surprisingly, there exists very little work that studies theoretically the competitive effects of mergers in a context where firms can not only compete in the product market but also on investments. Of course, there exists a wide literature on the related issue of the effects of competition in general on investments and on innovations. ${ }^{5}$ However, this literature analyzes what happens to investments when some proxy variable for competition intensifies or relaxes symmetrically for all firms, whereas we explicitly study the effect of a merger, which is an inherently asymmetric change: two firms combine their assets whereas the competitive environment (for instance the toughness of competition or the extent of product differentiation) is otherwise the same. Apart from better reflecting the nature of a merger, our model also allows to uncover the different effects that a merger has on insiders and outsiders, as well as its overall competitive impact (what is the effect on consumers?), a question which is less relevant in a literature which focuses on how investment and R\&D effort react to a symmetric shock to competition (consumers typically benefit/suffer as competition intensifies/softens).

\footnotetext{
${ }^{1}$ See the European Commission decisions on the Hutchison/Orange (Austria), Hutchison/Telefonica Ireland, Telefonica Deutschland/EPlus, TeliaSonera/Telenor, Hutchison 3G/Telefonica UK, and H3G Italy/Wind cases.

${ }^{2}$ Like the Federal Trade Commission (FTC) and the Department of Justice in the United States, the European Commission requires efficiencies to be verifiable, merger-specific, and beneficial to consumers, the three being cumulative conditions. This implies that efficiency claims need to be fully documented, that synergies that could be achieved through less anticompetitive means (e.g., via internal growth or via a Network-Sharing Agreement) would not be recognized, and that savings on fixed costs would not be accepted as they would not lead to lower prices.

${ }^{3}$ See for instance Daniel Thomas and Alex Barker, "Telecoms: Europeans scrambled signal", Financial Times, 30 June 2014; "Together we stand", The Economist, 22 August 2015; "Britain must not go from four to three in mobile", Financial Times, 2 February 2016. See also the discussion in Faccio and Zingales (2017).

${ }^{4}$ See the "Horizontal Merger Guidelines" by the U.S. Department of Justice and FTC, August 2010. In the recent DowChemical/DuPont case, for instance, the European Commission found that the merger would have significantly reduced the incentives to invest in $R \& D$ in the pesticide market, and hence imposed a major divestiture by DuPont as a condition for clearance. See European Commission Press Release of 27 March 2017 at http://europa.eu/rapid/press-release_IP-17-772_en.htm.

${ }^{5}$ Vives (2008) reviews this literature and studies a range of models to identify these effects. For more recent contributions in this line of research, see also Schmutzler (2013), Lopez and Vives (2016), and Marshall and Parra (2016).
} 
In this paper, we study the competitive impact of mergers in a setting where firms set both investment levels and prices, and where at the benchmark - that is, absent the merger - firms sell one differentiated product, whereas the merger will create a new multi-product firm which owns two product varieties, thereby breaking the symmetry in the industry.

As we shall see, our analysis strongly suggests that - under no or weak enough efficiency savings - a merger will reduce aggregate investments and harm consumers. Interestingly, this net effect will be the result of the decrease in investment and rise in prices on the side of the merging parties (the "insiders"), and the increase in investments, with prices which may either increase or decrease on the side of the "outsiders" to the merger.

We find that it is only when merger-driven cost savings in investments are sufficiently strong that the merger will be pro-competitive, which confirms - in a setting where firms compete not only in the product market but also in investments - the well-known result that a merger harms consumers unless there are sufficiently strong efficiency gains. ${ }^{6}$

Let us now be more specific about what we do in the paper. We analyze a game where firms choose cost-reducing investments and prices simultaneously. This allows us to abstract from strategic considerations inherent to sequential games and it is equivalent to an environment in which investment decisions are unobservable. Within a general model - for weak or no efficiency gains - the merger will always result in the insiders raising their prices and reducing their investments. This is ultimately due to the well-known market power effect of the merger: the merged entity internalizes that a price decrease in one of its products will reduce the demand of the other product it sells, and this determines an upward pressure in prices relative to the benchmark where all firms are independent. In turn, higher prices will lead to a lower quantity sold by the insiders, and a lower marginal revenue from investing for the insiders, whose investments will therefore decrease.

In the standard models of mergers with price-setting firms and where investments are not considered, outsiders' prices also increase due to strategic complementarity. But this is not always the case in our model. The merger does not directly affect the outsiders' first-order conditions, and when the insiders increase their prices, this will tend to increase outsiders' prices as well. But since outsiders' prices increase less, their demand tends to increase (their market share will rise for sure), and this will increase their (cost-reducing) investment levels. Two different effects are therefore at work: one which tends to increase their prices, and the other, through lower costs, which tends to decrease them. At equilibrium, outsiders' prices may either increase or decrease, and indeed we shall show that either outcome may arise according to the demand assumptions made.

Since the merger may have different effects on insiders' and outsiders' prices and investments, and since firms are selling differentiated products, it is not a priori clear what are the net effects of the merger. To answer this question, we first transform our original game - in which each firm chooses two variables (prices and investments) - into one in which each firm chooses only one variable. Next, we resort to an aggregative game theory formulation, which is possible whenever the payoff of a player depends on its own action and an additively separable aggregate of all players' actions (Selten, 1970). ${ }^{7}$

\footnotetext{
${ }^{6}$ See Farrell and Shapiro (1990), who offer a general treatment in a homogenous goods model; or Motta (2004: chapter 5) for a textbook presentation (based on a differentiated goods model with price competition).

${ }^{7}$ We use the oligopolistic aggregative game toolkit developed in Anderson et al. (2016) (see Anderson and Peitz, 2015, for an application to two-sided markets). Nocke and Schutz (2016) develop the aggregative game
} 
This allows us to establish that - absent efficiency gains - the merger has a negative impact on consumer surplus. ${ }^{8}$ This result holds for all classes of demand functions which satisfy the Independence of Irrelevant Alternatives, or IIA, property, like the CES and the logit demand models. We show it also holds in standard parametric product differentiation models - such as the Shubik-Levitan, and the Salop circle models - which do not satisfy the IIA property. We also find a sufficient condition for which the merger decreases total investments. Finally, we demonstrate that - as expected - the merger will be pro-competitive and investment-boosting if it allows firms to benefit from strong enough efficiency gains in R\&D.

We then extend our analysis in several directions. First, we consider the case where firms offer asymmetric goods, and confirm that - absent efficiency gains - a merger between any two of them will reduce consumer welfare. We also find sufficient conditions for the merger to reduce aggregate investments.

Second, we study the effects of a merger when firms undertake quality-enhancing investments. Within a general model, the results are a priori ambiguous: on the one hand, by raising prices the merger will increase the marginal profitability of investments; on the other, the merged entity will internalize the fact that increasing the quality of one product will reduce attractiveness (and profits) of its other product, and this reduces its incentive to invest. However, we prove that there exist two broad classes of models with quality-enhancing investments which turn out to be equivalent to the models with cost-reducing investments we have discussed above. For such classes of models, which include popular vertical product differentiation models, the same conclusions as above (namely, that the merger harms consumers) will therefore apply.

Third, we consider the case where investments give rise to involuntary spillovers (in our base model we assume instead that firms can fully appropriate their investments) and show that the existence of such spillovers shares some similarity with efficiency gains: since the merger allows firms to internalize them, higher spillovers lead to stronger incentives to invest by the merged entity.

Fourth, we consider a sequential game (firms first invest, their choice is observed by all, and then choose prices). The presence of strategic effects makes it difficult to establish propositions of general validity about the effects of the merger (and an aggregative game theory formulation for the sequential game is not possible). Nonetheless, the analysis of parametric models confirms the qualitative results found for the simultaneous moves case: the merger harms consumers; it increases prices and decreases investments of the insiders; it increases investments of the outsiders; and it may either decrease or increase outsiders' prices.

Finally, the reference to the mobile telephony industry raises the question whether it is possible to benefit from savings in the investment outlays without a full-fledged merger. Several national regulatory authorities in the EU and elsewhere have often allowed MNOs to engage

approach to study oligopolistic competition with multi-product firms, but their assumption that there are no fixed costs makes it difficult to apply their setting to our problem.

${ }^{8}$ We call a merger "anticompetitive" if it reduces consumer surplus. This is the standard adopted by the US and European competition agencies when they screen mergers. Indeed, the US Horizontal Merger Guidelines focus on the effect of a merger on customers and efficiency gains are accepted only to the extent that they will lead to lower prices. Similarly, in assessing both agreements and mergers, the European Commission admits only cost savings that are passed on to consumers. There is a debate as to whether agencies should instead adopt a total welfare standard. See e.g. Neven and Röller (2005), Farrell and Shapiro (2006), and Pittman (2007). For completeness we shall also indicate - when we are able to identify them - the effects of the merger on total surplus. For instance, we shall show that in the Salop model total surplus may increase with the merger. 
in Network Sharing Agreements (NSAs), whereby they share different elements of the network infrastructure and possibly of the spectrum ${ }^{9}$ while continuing to behave independently at the retail level. We model NSAs as R\&D cooperative agreements (see, e.g., d'Aspremont and Jacquemin, 1988): firms participating in the agreement decide investments to maximize joint profits, but they behave non-cooperatively when setting prices. The assumption that investments are taken cooperatively is consistent with the observation that, typically, the contract signed between NSA parties specifies the volume of future investments that each party is to undertake under the agreement. This practice also leaves limited room to free-riding. Moreover, we assume that prices are set non-cooperatively, as otherwise the NSA would be equivalent to a full-fledged merger. ${ }^{10}$ With simultaneous moves and efficiency gains, we show that the NSA increases consumer welfare with respect to the benchmark. ${ }^{11}$ This means that the NSA raises consumer welfare with respect to any merger that harms consumer surplus (i.e., those mergers that come with small efficiency gains). Instead, both the NSA and the merger raise welfare when efficiency gains are large. ${ }^{12}$

To summarize, by referring back to the arguments used by the mobile network operator industry, the claim that mergers promote investment because consolidation creates higher incentives to invest appears unfounded in the light of our analysis. Only if there are sufficiently large R\&D efficiency gains from the merger, will it be beneficial. But of course whether the 'if' applies is an empirical fact that should be verified case by case, as already foreseen by the current rules on merger control in major jurisdictions, like the US and the EU.

Let us now briefly mention the relationship between our paper and related branches of the literature other than those mentioned above. A complementary perspective to our analysis is offered by the literature studying dynamic oligopoly games. ${ }^{13}$ Specifically, Mermelstein et al. (2015) study the impact of mergers on the evolution of an industry, and derive the optimal dynamic merger policy in a model with capital accumulation and economies of scale. Differently from our model, in their setting two firms bargain over a merger to monopolize the industry. These firms invest to accumulate capital and exploit scale economies. Post-merger, an entrant appears in the market with zero capital. (Apart from having a different aim, their assumptions of homogenous goods and free entry clearly differentiate their environment from ours.) They find that the antitrust authority should depart from the myopic policy suggested by Nocke and Whinston (2010), and instead undertake a more restrictive policy.

As for the empirical literature on the effects of mergers on investments, it is also quite scant, and does not offer clear insights on what are the likely effects of the merger. ${ }^{14}$ Of course, there

\footnotetext{
${ }^{9}$ There exist several types of NSAs, from passive NSAs where the firms just share the site (say, each firm has its own equipment but they put it on the same mast), to active NSAs where active elements are shared, which in their more extreme form also include sharing the spectrum.

${ }^{10}$ Our approach to modeling NSAs also implicitly assumes that NSA members have free access to the joint infrastructure - or whatever is the outcome of the jointly decided investments.

${ }^{11}$ Of course, it is conceivable that for contractual or technological reasons the NSA may not allow partner firms to achieve the scale economies that can be obtained when there is a full merger. But this is a factual and case-specific claim that firms would have to substantiate in a merger investigation.

${ }^{12}$ When resorting to standard product differentiation models (like the Shubik-Levitan demand function, and the Salop circle model) we also show that the NSA results in lower prices and higher consumer and total welfare than the merger.

${ }^{13}$ See, among others, Ericson and Pakes (1995), Gowrisankaran (1999), Fershtman and Pakes (2000).

${ }^{14}$ Ornaghi (2009) finds that mergers in the pharmaceutical industry decreases innovation. Focarelli and Panetta (2003) find that mergers in the Italian retail banking industry have raised prices in the short-run but
} 
is also a large empirical literature on how competition impacts upon innovations, investments and productivity, ${ }^{15}$ but again a merger is not tantamount to a general shift in the competitive pressure in a sector.

The paper continues thus. Section 2 studies the effects of the merger within a simultaneous moves model with cost-reducing investments. In Section 3, we extend the analysis by considering asymmetric firms, quality-enhancing investments, involuntary spillovers, a sequential moves game, and a Network-Sharing Agreements (or Research Joint Venture). Section 4 concludes.

\section{A model of price competition and cost-reducing in- vestments}

We use a model of Bertrand oligopoly with differentiated goods and $n \geq 2$ firms. Demand for the good produced by firm $i$ is given by $q_{i}\left(p_{i}, \bar{p}_{-i}\right)$, where $p_{i}$, which is assumed to take values in a compact interval, ${ }^{16}$ is the price of firm $i$ and $\bar{p}_{-i}$ is the $(n-1) \times 1$ vector of prices set by firms $-i \neq i$. The number of independent firms, $n$, is exogenous, reflecting barriers to entry, although it changes with the merger. Function $q_{i}\left(p_{i}, \bar{p}_{-i}\right)$ is symmetric, ${ }^{17}$ strictly decreasing and twice continuously differentiable whenever $q_{i}>0$. As is standard, we also assume that demand of firm $i$ decreases in $p_{i}\left(\partial_{p_{i}} q_{i}\left(p_{i}, \bar{p}_{-i}\right)<0\right)$, goods are substitutes $\left(\partial_{p_{j}} q_{i}\left(p_{i}, \bar{p}_{-i}\right) \geq 0\right)$, and own price effects are larger than cross price effects $\left(\left|\partial_{p_{i}} q_{i}\left(p_{i}, \bar{p}_{-i}\right)\right|>\partial_{p_{j}} q_{i}\left(p_{i}, \bar{p}_{-i}\right)\right)$ - where $\partial_{p_{i}}$ and $\partial_{p_{i} p_{i}}^{2}$ denote, respectively, the first- and the second-order partial derivative with respect to $p_{i}$, for all $i=1, \ldots, n$.

Each firm $i$ simultaneously sets its price $p_{i}$ and its cost-reducing investment $x_{i}$ to maximize profits, given rivals' choices. In the model, $c\left(x_{i}\right)$ denotes firm $i$ 's marginal cost as function of $x_{i}$. We assume that $c^{\prime}<0, c^{\prime \prime} \geq 0, c^{\prime \prime \prime} \geq 0$ and $c(0)=c \geq 0$. We denote by $F\left(x_{i}\right)$ the fixed cost borne by firm $i$ to invest $x_{i}$, with $F(0)=0, F^{\prime} \geq 0, F^{\prime \prime} \geq 0$ and $F^{\prime \prime \prime} \geq 0$.

A merger between two firms $i$ and $k$ may give rise to cost savings in R\&D, which we will refer to as efficiency gains. The parameter $\lambda \in[0,1)$ captures the importance of these efficiency gains enjoyed by a merged entity, whose total cost is given by $F\left(x_{i}\right)+F\left(x_{k}\right)-\lambda G\left(x_{i}, x_{k}\right) \geq 0$, with $\partial_{x_{i}} G\left(x_{i}, x_{k}\right), \partial_{x_{k}} G\left(x_{i}, x_{k}\right) \geq 0$ and $\partial_{x_{i}} G(x, x)=\partial_{x_{k}} G(x, x) .{ }^{18}$ As we shall see, the following

decreased them in the long-run due to enhanced efficiency. Genakos et al. (2015) estimate an empirical model and use it to predict the impact of (hypothetical and symmetric) four-to-three mergers. They find that prices would increase, per-firm capital expenditures (a proxy for investments) would also increase, but no evidence of effects on total capital expenditures.

${ }^{15}$ See for instance the work by Aghion et al. (2005) which identifies an inverted-U shape relationship between competition and innovation, and Shapiro (2013) for a critique of their analysis; and the surveys by Bartelsman and Doms (2000) and Syverson (2011).

${ }^{16}$ Specifically, we bound prices by ruling out outcomes with negative payoffs.

${ }^{17}$ That is, the demand of firm $i$ when it sets a price equal to $p$ and all the other firms set a price equal to $z$ in vector $\bar{z}$ is the same as the quantity of a firm $j$ setting $p$ given that all other firms set a price equal to $z$ in vector $\bar{z}$ (i.e., $\left.q_{i}(p, \bar{z})=q_{j}(p, \bar{z})\right)$ for all $i, j$. If firms $i$ and $j$ merge, the condition for symmetry requires that firm $i$ 's quantity is the same as firm $j$ 's when $i$ and $j$ set $p$ and all other firms set $z$. In Section 3.1 we show our main results still hold when the assumption of symmetry is relaxed.

${ }^{18}$ In previous versions of the paper we modeled efficiency gains as affecting marginal costs of production: $c\left(x_{i}, x_{k}, \lambda\right)=c\left(x_{i}+I_{s} \lambda x_{k}\right)$, with $I_{s}=0$ when firms are independent and $I_{s}=1$ if they are merged. The results were qualitatively the same as those reported here. Note that in this section we assume that a firm is able to fully appropriate its own investments (for instance because they are fully protected by IPRs or property rights laws). In Section 3.3 we discuss the case of involuntary spillovers. 
conditions are necessary for the unicity of firms' investment value at equilibrium:

$$
F^{\prime}\left(x_{i}\right)-\lambda \partial_{x_{i}} G\left(x_{i}, x_{k}\right) \geq 0, F^{\prime \prime}\left(x_{i}\right)-\lambda \partial_{x_{i} x_{i}} G\left(x_{i}, x_{k}\right) \geq 0 .
$$

Roadmap of this section For the remaining part of this section, we proceed in the following way. In Section 2.1 we write the firms' maximization problem at the benchmark (i.e., if the merger does not take place), show that the firms' bi-dimensional (price and investment) variable problem can be written as a one-dimension (price) problem (we resort to this transformation throughout the paper), and that the benchmark equilibrium is unique for a general demand function under standard regularity assumptions. We then write the maximization problem and the FOCs in case of a merger, and explain why the characterization of the merger equilibrium is not a straightforward problem. Since part of the complexity is due to the interaction between insiders and outsiders to the merger, we start by abstracting from outsiders' reactions: Section 2.2 fully characterizes the effect of a merger to monopoly under a general demand function (to do so, we rely on the existence and uniqueness of the benchmark equilibrium previously established). Section 2.3 is the main section of the paper. It focuses on classes of demand functions such that a firm's payoff only depends on its own action and the sum of the actions of all the firms in the industry, which allows us to resort to an aggregative game theory formulation of the problem and to establish the main effects of the merger, notably on consumer surplus and on total investments. Finally, Section 2.4 analyzes specific functional form examples, both to consider models which do not satisfy the sufficient conditions under which some results hold, and to gain further insights on the effects of the merger, for instance on insiders' and outsiders' prices and investments, and on total surplus.

With the exception of Lemma 1, which describes the transformation of the "investmentand-price" firm's problem into a "only-price" problem, all the proofs are in the Appendix.

\subsection{Equilibrium analysis}

In what follows, we first analyze the benchmark (or status quo) case, where there are $n$ independent firms. Then, we study the effects of the merger, where two out of the $n$ firms merge.

\subsubsection{Benchmark with independent firms}

In the benchmark, each firm $i$ solves the following maximization problem:

$$
\max _{p_{i}, x_{i}} \tilde{\pi}_{i}\left(p_{i}, \bar{p}_{-i}, x_{i}\right)=\left(p_{i}-c\left(x_{i}\right)\right) q_{i}\left(p_{i}, \bar{p}_{-i}\right)-F\left(x_{i}\right), i=1, \ldots, n
$$

The associated first-order conditions (FOCs) are:

$$
\begin{aligned}
& \partial_{p_{i}} \tilde{\pi}_{i}=q_{i}\left(p_{i}, \bar{p}_{-i}\right)+\partial_{p_{i}} q_{i}\left(p_{i}, \bar{p}_{-i}\right)\left(p_{i}-c\left(x_{i}\right)\right)=0, \\
& \partial_{x_{i}} \tilde{\pi}_{i}=-c^{\prime}\left(x_{i}\right) q_{i}\left(p_{i}, \bar{p}_{-i}\right)-F^{\prime}\left(x_{i}\right)=0 .
\end{aligned}
$$

In order to ensure that the FOCs give rise to a unique symmetric equilibrium, one may follow two different approaches. The first one is to impose the regularity conditions on the bi-dimensional problem that firms solve (each firm needs to maximize profits with respect to both investments and prices). We may do this by invoking the assumptions in, e.g., Hefti (forthcoming). The second approach is to reduce the bi-dimensional problem into a game in 
which each firm chooses only its price. Indeed, as we show below, the FOC with respect to $x_{i}$ in (2) is independent of rivals' investment $x_{-i}$ and, under our assumptions, we can express $x_{i}$ as a function of the firm's quantity $q_{i}(\cdot, \cdot)$.

Since we need to make this transformation into a one-dimensional problem to write the $n$-firm aggregative formulation of the game that we use in Section 2.3, we follow the latter approach.

Lemma 1. For any given value of $\left(p_{i} \cdot \bar{p}_{-i}\right)$, there is a unique corresponding value of $x_{i}$, and each firm i's bi-dimensional (investment and price) maximization problem can be rewritten as one in a single choice variable (price).

Proof. Since there are no efficiency gains in the benchmark, the investment FOCs in (2) can be rewritten as:

$$
\partial_{x_{i}} \tilde{\pi}_{i}=-c^{\prime}\left(x_{i}\right) q_{i}\left(p_{i}, \bar{p}_{-i}\right)=F^{\prime}\left(x_{i}\right) \Longleftrightarrow-\frac{F^{\prime}\left(x_{i}\right)}{c^{\prime}\left(x_{i}\right)}=q_{i}\left(p_{i}, \bar{p}_{-i}\right) .
$$

We use $-F^{\prime}\left(x_{i}\right) / c^{\prime}\left(x_{i}\right) \equiv \phi\left(x_{i}\right)$. Since $F^{\prime}(\cdot) \geq 0, c^{\prime}(\cdot)<0, F^{\prime \prime}(\cdot) \geq 0$ and $c^{\prime \prime}(\cdot) \geq 0$, it follows that $\phi^{\prime}(\cdot) \geq 0$ :

$$
\phi^{\prime}\left(x_{i}\right)=\frac{\partial}{\partial x_{i}}\left(-\frac{F^{\prime}\left(x_{i}\right)}{c^{\prime}\left(x_{i}\right)}\right)=-\frac{\left(F^{\prime \prime}\left(x_{i}\right) c^{\prime}\left(x_{i}\right)-c^{\prime \prime}\left(x_{i}\right) F^{\prime}\left(x_{i}\right)\right)}{\left(c^{\prime}\left(x_{i}\right)\right)^{2}} \geq 0 .
$$

Hence, (3), together with the properties of $\phi(\cdot)$, implies that $\phi(\cdot)$ is invertible, and $x_{i}=$ $\phi^{-1}\left(q_{i}\left(p_{i}, \bar{p}_{-i}\right)\right) \equiv \chi\left(q_{i}\left(p_{i}, \bar{p}_{-i}\right)\right)$, and, by the properties of the inverse functions, $\chi^{\prime}(\cdot) \geq 0:{ }^{19}$ for any given value of $\left(p_{i} \cdot \bar{p}_{-i}\right)$, the equilibrium value of firm $i$ 's investment is uniquely determined by that firm's quantity.

We can then write firm $i$ 's profits as a function in a single choice variable:

$$
\left(p_{i}-c\left(\chi\left(q_{i}\left(p_{i}, \bar{p}_{-i}\right)\right)\right)\right) q_{i}\left(p_{i}, \bar{p}_{-i}\right)-F\left(\chi\left(q_{i}\left(p_{i}, \bar{p}_{-i}\right)\right)\right) .
$$

Q.E.D.

The lemma shows that $x_{i}$ is a function of the firm's quantity $q_{i}$ according to the injective relationship $x_{i}=\chi\left(q_{i}\right)$, with $\chi^{\prime}(\cdot) \geq 0$ and $\chi(0)=0$. Hence, the problem of firm $i$ can be rewritten as

$$
\begin{aligned}
& \max _{p_{i}} \pi_{i}\left(p_{i}, \bar{p}_{-i}\right) \equiv\left(p_{i}-c\left(\chi\left(q_{i}\left(p_{i}, \bar{p}_{-i}\right)\right)\right)\right) q_{i}\left(p_{i}, \bar{p}_{-i}\right)-F\left(\chi\left(q_{i}\left(p_{i}, \bar{p}_{-i}\right)\right)\right), \\
& \text { subject to } \\
& x_{i}=\chi\left(q_{i}\left(p_{i}, \bar{p}_{-i}\right)\right) .
\end{aligned}
$$

In what follows, we assume that function $\pi_{i}$ satisfies the standard assumptions ensuring that a unique regular symmetric interior equilibrium exists (see, e.g., Vives, 1999). Specifically, these assumptions require that the FOCs are downward sloping and have a unique solution. ${ }^{20}$ Dropping functional notation for $q_{i}$, firm $i$ 's FOC with respect to $p_{i}$ is:

$$
\partial_{p_{i}} \pi_{i}=\left(p_{i}-c\left(\chi\left(q_{i}\right)\right)\right) \partial_{p_{i}} q_{i}+q_{i}-\frac{d c\left(\chi\left(q_{i}\right)\right)}{d p_{i}} q_{i}-\frac{d F\left(\chi\left(q_{i}\right)\right)}{d p_{i}}=0
$$

\footnotetext{
${ }^{19}$ Specifically, since $\phi$ is differentiable and $\chi$ is its inverse, $\phi^{\prime}=1 / \chi^{\prime}$ and $\operatorname{sign}\left\{\phi^{\prime}\right\}=\operatorname{sign}\left\{\chi^{\prime}\right\}$.

${ }^{20}$ We then check that these conditions are satisfied in the parametric models we use to illustrate our results.
} 
where, invoking the envelope theorem,

$$
\begin{aligned}
\frac{d c\left(\chi\left(q_{i}\right)\right)}{d p_{i}} q_{i}+\frac{d F\left(\chi\left(q_{i}\right)\right)}{d p_{i}} & =q_{i} c^{\prime}\left(\chi\left(q_{i}\right)\right) \chi^{\prime}\left(q_{i}\right) \partial_{p_{i}} q_{i}+F^{\prime}\left(\chi\left(q_{i}\right)\right) \chi^{\prime}\left(q_{i}\right) \partial_{p_{i}} q_{i} \\
& =\left[c^{\prime}\left(\chi\left(q_{i}\right)\right) q_{i}+F^{\prime}\left(\chi\left(q_{i}\right)\right)\right] \chi^{\prime}\left(q_{i}\right) \partial_{p_{i}} q_{i} \\
& =0
\end{aligned}
$$

by the equilibrium condition in (6) and $q_{i}=-F^{\prime} / c^{\prime}$ (see equation (3) in the proof of Lemma 1). Then, the FOC in (7) can be written as

$$
\partial_{p_{i}} \pi_{i}=\left(p_{i}-c\left(\chi\left(q_{i}\right)\right)\right) \partial_{p_{i}} q_{i}+q_{i}=0 .
$$

Under the assumptions above, these FOCs are sufficient for optimality. After imposing symmetry, the solution of (8) gives the equilibrium value of the price in the benchmark, $p^{b}$. Plugging this $p^{b}$ into (6) gives us the unique symmetric equilibrium of a firm's investment in the benchmark, $x^{b}{ }^{21}$

Lemma 2. In the benchmark with $n$ independent firms and simultaneous moves, there exists a unique symmetric equilibrium that features each firm setting a price $p_{i}=p^{b}$ and investing $x_{i}=x^{b}$, with $i=1, \ldots, n$.

Before proceeding with the analysis of the merger, we note that, after accounting for the dynamic efficiencies generated by investments, our pricing model may exhibit strategic complementarity or substitutability depending on the primitives of our game. Indeed, the cross derivative of $\pi_{i}$ with respect to $p_{i}$ and $p_{j}$ is given by

$$
\partial_{p_{i} p_{j}}^{2} \pi_{i}=\left(p_{i}-c\left(\chi\left(q_{i}\right)\right)\right) \partial_{p_{i} p_{j}}^{2} q_{i}+\partial_{p_{j}} q_{i}-c^{\prime}\left(\chi\left(q_{i}\right)\right) \chi^{\prime}\left(q_{i}\right) \partial_{p_{j}} q_{i} \partial_{p_{j}} q_{j}, \forall j \neq i,
$$

with $c^{\prime}<0$ and $\chi^{\prime} \geq 0$ - while it would be $\left(p_{i}-c\right) \partial_{p_{i} p_{j}}^{2} q_{i}+\partial_{p_{j}} q_{i}$ absent investments. The sign of (9) depends on the shape of demand and cost functions. Thus, fixing $c=c\left(\chi\left(q_{i}\right)\right)$, the "dynamic" reaction function solving (8) may slope downward or upward.

\subsubsection{Merger between firm $i$ and firm $k$}

Next, consider the merging firms' problem. Recall that the merger may generate efficiency gains (measured by $\lambda$ ) at the investment stage. Merging firms $i$ and $k$ choose prices and investments to maximize $\tilde{\pi}_{i, k} \equiv \tilde{\pi}_{i}\left(p_{i}, \bar{p}_{-i}, x_{i}\right)+\tilde{\pi}_{k}\left(p_{k}, \bar{p}_{-k}, x_{k}\right)+\lambda G\left(x_{i}, x_{k}\right)$ :

$$
\begin{aligned}
\max _{p_{i}, p_{k}, x_{i}, x_{k}} \tilde{\pi}_{i, k}=\left(p_{i}-c\left(x_{i}\right)\right) q_{i}\left(p_{i}, \bar{p}_{-i}\right)+\left(p_{k}-c\left(x_{k}\right)\right) q_{k}\left(p_{k}, \bar{p}_{-k}\right) \\
\\
-F\left(x_{i}\right)-F\left(x_{k}\right)+\lambda G\left(x_{i}, x_{k}\right), \quad i, k=1, \ldots, n, i \neq k .
\end{aligned}
$$

The FOCs with respect to $p_{i}$ and $x_{i}$ are (we omit those for $p_{k}$ and $x_{k}$, which are symmetric):

$$
\begin{aligned}
& \partial_{p_{i}} \tilde{\pi}_{i, k}=q_{i}\left(p_{i}, \bar{p}_{-i}\right)+\partial_{p_{i}} q_{i}\left(p_{i}, \bar{p}_{-i}\right)\left(p_{i}-c\left(x_{i}\right)\right)+\partial_{p_{i}} q_{k}\left(p_{k}, \bar{p}_{-k}\right)\left(p_{k}-c\left(x_{k}\right)\right)=0, \\
& \partial_{x_{i}} \tilde{\pi}_{i, k}=-\partial_{x_{i}} c\left(x_{i}\right) q_{i}\left(p_{i}, \bar{p}_{-i}\right)-F^{\prime}\left(x_{i}\right)+\lambda \partial_{x_{i}} G\left(x_{i}, x_{k}\right)=0 .
\end{aligned}
$$

\footnotetext{
${ }^{21}$ The following lemma holds for any demand function which satisfies the (mild) regularity conditions given above. In Section 2.3 we shall state a similar lemma which will hold only for demand functions which are consistent with an aggregative game formulation.
} 
Moreover, an outsider firm $j \neq i, k$ solves the following problem:

$$
\max _{p_{j}, x_{j}} \tilde{\pi}_{j}\left(p_{j}, \bar{p}_{-j}, x_{j}\right)=\left(p_{j}-c\left(x_{j}\right)\right) q_{j}\left(p_{j}, \bar{p}_{-j}\right)-F\left(x_{j}\right),
$$

so that its FOCs are isomorphic to those of a firm in the benchmark, independently of the value of the efficiency gains $\lambda$, which affect the merging firms:

$$
\begin{aligned}
& \partial_{p_{j}} \tilde{\pi}_{j}=q_{j}\left(p_{j}, \bar{p}_{-j}\right)+\partial_{p_{j}} q_{j}\left(p_{j}, \bar{p}_{-j}\right)\left(p_{j}-c\left(x_{j}\right)\right)=0, \\
& \partial_{x_{j}} \tilde{\pi}_{j}=-c^{\prime}\left(x_{j}\right) q_{j}\left(p_{j}, \bar{p}_{-j}\right)-\partial_{x_{j}} F\left(x_{j}\right)=0 .
\end{aligned}
$$

Let us make some preliminary observations following simple inspection of the FOCs in the benchmark and merger configurations (in the following subsections we shall dwell more upon the effects mentioned here). First of all, both the price and investment FOCs of the outsiders do not change with the merger, so it will affect the outsiders' choices only through their best responses to the insiders' post-merger optimal choices.

Second, absent efficiency gains $(\lambda=0)$, the investment FOCs of the insiders are the same too, with and without the merger. Investments will be affected by changes in the quantities: in particular, the lower $q_{i}\left(p_{i}, \bar{p}_{-i}\right)$ the lower the marginal revenue from investing and hence the lower investment levels at equilibrium. With efficiency gains $(\lambda>0)$, instead, the merger will decrease investment costs relative to the benchmark, and stimulate insiders' investments, which in turn will decrease marginal costs of production $c\left(x_{i}\right)$ and will tend to decrease prices.

Third, absent efficiency gains the merger effects will be mainly driven by the new term which appears in the insiders' price FOCs $\left(\partial_{p_{i}} q_{k}\left(p_{k}, \bar{p}_{-k}\right)\left(p_{k}-c\left(x_{k}\right)\right)>0\right)$ : when setting the price of product $i$, the merged entity will internalize the impact of $p_{i}$ on the quantity demanded of good $k$. This is the standard market power effect of mergers that we all know, and that will tend to raise prices after the merger. With efficiency gains, this effect may be outweighed by the decrease in marginal costs identified above.

While these forces are clear at first sight, the identification of the net effect of the merger on all the relevant variables at equilibrium is not straightforward. Consider for instance the simpler case of no efficiency gains. The insiders' prices will increase with the merger. With strategic complementarity on prices, we know that this will tend to increase outsiders' prices as well, but (under regularity conditions) to a lower extent. Hence, outsiders' quantities will tend to rise because outsiders set a better relative price. But, since the higher $q_{j}\left(p_{j}, \bar{p}_{-j}\right)$ the higher the investments $x_{j}$, this will tend to decrease the production costs of outsiders, which feeds back into the outsiders' price FOCs and will tend to decrease their prices. A priori, we are not able to say whether the ultimate effect will be to increase or decrease the outsiders' prices.

Furthermore, although intuitively the main effects of the merger will come from the direct price increase of the insiders and the following effects will be indirect and of a lower order of magnitude, we need to find a rigorous framework to assess the net effects of the merger, also taking into account that with differentiated products - unlike with homogenous goods - we need to aggregate the effects deriving from the quantities sold of different products. This is where the aggregative game formulation we adopt in Section 2.3 will be of help. Before that, though, we analyze the effects of a merger to monopoly. 


\subsection{A merger to monopoly}

Let us analyze the effect of a merger in an industry where there are only two firms, but without making restrictive assumptions on the demand function. Focusing on two firms allows us to disregard the indirect effects which may take place through the outsiders to the merger.

We first establish that, absent merger-induced efficiency gains $(\lambda=0)$, the merger to monopoly raises prices and reduces investment. Then, we consider efficiency gains $(\lambda>0)$ and identify the level of $\lambda$ such that the merger will expand the firms' investments and benefit consumers. Proceeding as in Lemma 1, the merging firms' problem in prices and investments can be rewritten as a problem in $p_{i}$ and $p_{k}$ only; thus, the corresponding (standard) second order conditions are:

$$
(A 0): \partial_{p_{i} p_{i}}^{2} \pi_{i, k}<0, \partial_{p_{k} p_{k}}^{2} \pi_{i, k}<0,\left(\partial_{p_{i} p_{i}}^{2} \pi_{i, k}\right)\left(\partial_{p_{k} p_{k}}^{2} \pi_{i, k}\right)>\left(\partial_{p_{i} p_{k}}^{2} \pi_{i, k}\right)^{2},
$$

where $\pi_{i, k}$ is the merged entity's profit function. In what follows, we assume that these conditions hold true both with and without efficiency gains at any interior maximum. Due to the absence of outsiders, they will guarantee that the FOCs are sufficient for optimality.

\subsubsection{No efficiency gains: $\lambda=0$.}

Consider first what happens when efficiency gains are absent: $\lambda=0$. The proposition below establishes that the merger will decrease investments and increase prices, thereby unambiguously harming consumers.

We set up the merging firms' maximization problem: ${ }^{22}$

$$
\begin{array}{ll}
\max _{p_{i}, p_{k}} & \pi_{i, k} \equiv \pi_{i}\left(p_{i}, p_{k}\right)+\pi_{k}\left(p_{k}, p_{i}\right) \\
& \text { subject to } \\
& x_{i}=\chi\left(q_{i}\left(p_{i}, p_{k}\right)\right) \\
& x_{k}=\chi\left(q_{k}\left(p_{k}, p_{i}\right)\right),
\end{array}
$$

where $\pi_{i}$ is defined in (5). Solving this problem, and considering the benchmark above under $n=2$, yields the following proposition:

Proposition 1. With simultaneous moves and absent merger-induced efficiency gains, a merger to monopoly will raise the equilibrium price and decrease investments.

Intuitively, this result is the consequence of the effects discussed above: given the internalization of the price effect of one product on the demand of the other, at the price and investment levels of the benchmark equilibrium (given by Lemma 2) the merged firms will want to raise prices. This will reduce quantities sold which, in turn, will make them want to decrease investments. But since lower investments will imply higher production cost, this effect will reinforce the increasing effect on the price.

\footnotetext{
${ }^{22}$ Note that, if $\lambda=0$, the merging firm's FOCs for investments is isomorphic to the one in the benchmark in (2).
} 


\subsubsection{Efficiency gains: $\lambda>0$.}

Next, consider the case where $\lambda>0$. The following lemma establishes a monotonic relationship between the level of efficiency gains $\lambda$ and the equilibrium values of the merger: as $\lambda$ increases, investments increase and prices fall. Note that this lemma holds for any $\lambda$, and therefore also describes what happens when efficiency gains increase from $\lambda=0$.

Lemma 3. Consider an equilibrium solution $\left(p^{m}(\lambda), x^{m}(\lambda)\right)$ of the merged entity problem corresponding to a given level $\lambda$ of efficiency gains. As $\lambda$ increases, the merger equilibrium price will decrease and the merger equilibrium investment will increase: $\partial_{\lambda} p^{m}(\lambda)<0, \partial_{\lambda} x^{m}(\lambda)>0$.

To understand the lemma, suppose that there are no efficiency gains and that the merged entity is at its optimal price and investment choice. Now, if $\lambda$ became positive (no matter how small), the merged entity will find it optimal to increase investments, because they are cheaper. As a result, production costs will be lower, which will push the firm to lower prices (which, through higher quantities demanded, will push it to further adjust investments upwards, and so on). So, the higher the efficiency gains the lower prices and the higher investment levels.

Next, we identify a level of efficiency gains such that investment levels are the same with and without merger.

Lemma 4. With simultaneous moves, if the level $\lambda^{b}$ of efficiency gains is such that a merger to monopoly results in the same level of investments as in the benchmark, $x^{m}\left(\lambda^{b}\right)=x^{b}$, then at $\lambda^{b}$, the merger will result in higher prices than at the benchmark: $p^{m}\left(\lambda^{b}\right)>p^{b}$.

\subsubsection{Comparisons between benchmark and merger equilibrium}

Armed with the two previous lemmas we can now characterize the benchmark and the merger equilibrium solutions as a function of the efficiency gains. In particular, we know that for $\lambda=0$ the merger leads to lower investments and higher prices; that as $\lambda$ increases, the benchmark solutions do not change (when firms are independent they do not benefit from efficiency gains), and the merger performs better (prices decrease and investments increase with $\lambda$ ); that there exists a level of efficiency gains $\lambda^{b}$ such that the investment at the merger equilibrium equals the investment at the benchmark equilibrium, but that at that level the merger price is still higher than at the benchmark. Hence, by the monotonicity of the solutions with respect to $\lambda$, if there exists a $\widetilde{\lambda}>\lambda^{b}$ such that $p^{m}(\widetilde{\lambda})=p^{b}$ then it must be that $x^{m}(\widetilde{\lambda})>x^{b}$. This also implies that even if the merger was showed to entail sufficient efficiency gains to increase investments, this may not be sufficient to infer that the merger is competitively neutral (not to say beneficial): there will exist an interval $\lambda \in\left(\lambda^{b}, \widetilde{\lambda}\right)$ for which the merger raises investments but also the prices, thereby affecting negatively consumer welfare.

The following summarizes this discussion.

Proposition 2. In a merger to monopoly, for low efficiency gains, $0 \leq \lambda<\lambda^{b}$, the merger will lead to lower investments and higher prices; for intermediate levels, $\lambda^{b} \leq \lambda<\widetilde{\lambda}$, the merger (weakly) increases investments but increases prices; only for high efficiency gains $(\lambda \geq \widetilde{\lambda})$ will the merger (weakly) reduce prices and be pro-competitive. 


\subsection{The effects of a merger in a $n$-firm industry}

In this section, we analyze the consequences of the merger in an industry with $n \geq 3$ firms. We will study how prices and investments change after the merger by exploiting methodologies borrowed from aggregative game theory (e.g., Selten, 1970; Jensen, 2010; Cornes and Hartley, 2012). In line with the rest of the paper, we use the assumption of symmetry. ${ }^{23}$

By Lemma 1, we can recast our price-and-investment simultaneous game into a singlevariable problem $\left(p_{i}\right)$, under the condition that $x_{i}=\chi\left(q_{i}\left(p_{i}, \bar{p}_{-i}\right)\right)$ for all $i$. This allows us to write the firm's profit maximization problem as an aggregative game, that is, a game in which a firm's payoff $\pi_{i}$ is a function of its own action $\left(a_{i}\right)$ and the sum of the actions of all the $n$ firms in the industry, the aggregate, $A=\sum_{i=1}^{n} a_{i}$.

Specifically, we focus on the classes of quasi-linear indirect utility functions of the following type:

$$
V(\bar{p})=\sum_{i \in N} h\left(p_{i}\right)+\Psi\left(\sum_{i \in N} \psi\left(p_{i}\right)\right),
$$

with $\psi, \Psi$ and $h\left(p_{i}\right)$ continuous and thrice continuously differentiable, $\psi^{\prime}\left(p_{i}\right)<0$ and $\Psi^{\prime}(\cdot)>0$. By Roy's identity, the ensuing demand function for product $i$ is given by

$$
q_{i}\left(p_{i}, \bar{p}_{-i}\right)=-h^{\prime}\left(p_{i}\right)-\psi^{\prime}\left(p_{i}\right) \Psi^{\prime}\left(\sum_{j \in N} \psi\left(p_{j}\right)\right) .
$$

Nocke and Schutz (2016) show that, with $n \geq 3$ asymmetric products, this demand function has an aggregative formulation - a fortiori, this result extends to our framework with $n \geq 3$ symmetric goods. In particular, since $\psi(\cdot)$ is strictly decreasing, we can rewrite the demand in (13) as a function of $a_{i} \equiv \psi\left(p_{i}\right)$ and its summation $A \equiv \sum_{i \in N} \psi\left(p_{i}\right)$ only, i.e., $q_{i}\left(a_{i}, A\right)=$ $-h^{\prime}\left(\psi^{-1}\left(a_{i}\right)\right)-\psi^{\prime}\left(\psi^{-1}\left(a_{i}\right)\right) \Delta^{\prime}(A)$. Accordingly, we will rewrite $\pi_{i}\left(p_{i}, \bar{p}_{-i}\right)$ as $\pi_{i}\left(A, a_{i}\right)$.

Since the interval of values of $p_{i}$ is compact, so is the one of $a_{i}$. We further assume that $d q_{i} / d a_{i}>0$, with $d q_{i} / d a_{i}=\partial_{a_{i}} q_{i}+\partial_{A} q_{i}, \partial_{a_{j}} q_{i}<0, i \neq j$, and $d q_{i} / d a_{i}+\partial_{a_{j}} q_{i}>0 .{ }^{24}$

We now discuss the properties of our demand system:

1. If $h^{\prime}\left(p_{i}\right)=0$, the demand in (13) satisfies IIA, because $q_{i} / q_{j}=\psi^{\prime}\left(p_{i}\right) / \psi^{\prime}\left(p_{j}\right)$. Prominent examples of demand functions that fall into this category are the logit and CES demand models. As far as the logit is concerned, recall that

$$
q_{i}=\frac{\exp \left\{\left(s-p_{i}\right) / \mu\right\}}{\exp \left\{\left(s_{0}-p_{0}\right) / \mu\right\}+\sum_{j=1}^{n} \exp \left\{\left(s-p_{j}\right) / \mu\right\}},
$$

where $s_{0}, s \in \mathbb{R}$ are quality parameters, $\mu$ the degree of preference heterogeneity, and the outside good $j=0$ has a price $p_{0}=0$. It can be written in aggregative terms by setting $a_{i}=\exp \left\{\left(s-p_{i}\right) / \mu\right\}$. The CES function features $q_{i}=p_{i}^{-r-1} / \sum_{j=1}^{n} p_{j}^{-r}$, where $r=\rho /(1+\rho)$ and $\rho$ measure products' substitutability. Its aggregative formulation requires $a_{i}=p_{i}^{-r}$.

\footnotetext{
${ }^{23}$ As discussed in Section 3.1, the main results below extend to the more general case with asymmetric firms.

${ }^{24}$ These assumptions are satisfied by the three specific demand functions we consider as main examples - CES, logit and linear demand.
} 
2. If $h^{\prime}\left(p_{i}\right) \neq 0$, the demand system fails to satisfy the IIA property. A function that falls into this category is the Shubik-Levitan demand system,

$$
q_{i}=\frac{\left(\alpha-p_{i}\right)[1+(n-1) \gamma]-\gamma \sum_{j=1}^{n}\left(\alpha-p_{j}\right)}{(1-\gamma)[1+(n-1) \gamma]}
$$

where $\alpha$ is the intercept and $\gamma \in(0,1)$ measures product substitutability. In this case, $a_{i}=\left(\alpha-p_{i}\right)$.

As we shall see, whether the IIA property holds has consequences for our welfare analysis. The reason is that under the IIA consumer surplus only depends on $A$; thus, proving that the aggregate falls with the merger will imply a fall in consumer surplus.

Outline of this sub-section We shall analyze this aggregative game formulation by applying the toolkit developed in Anderson et al. (2016). First, we state the assumptions behind the aggregative game analysis; second, we construct firm $i$ 's inclusive reaction function $\tilde{r}_{i}(A)$ to the aggregator $A$ (Selten, 1970). We shall then write the aggregate inclusive reaction $\sum_{i=1}^{n} \tilde{r}_{i}(A)$. The equilibrium will then be determined as the fixed point of the problem $\sum_{i=1}^{n} \tilde{r}_{i}(A)=A$. The same procedure will be applied for both the benchmark and the merger, and we shall then proceed to the analysis of the effects by comparing the two equilibria. After carrying out the analysis in general, we shall develop the full analysis with a particular demand function, as an illustration of the methodology.

\subsubsection{Assumptions on payoffs}

In the aggregative formulation of the game, the profit function of firm $i$ is

$$
\pi_{i}\left(A, a_{i}\right)=\left(\psi^{-1}\left(a_{i}\right)-c\left(\chi\left(q_{i}\left(A, a_{i}\right)\right)\right)\right) q_{i}\left(A, a_{i}\right)-F\left(\chi\left(q_{i}\left(A, a_{i}\right)\right)\right),
$$

with $x_{i}=\chi\left(q_{i}\left(A, a_{i}\right)\right)$ for all $i$.

Let $A_{-i}=A-a_{i}$ denote the sum of all firms' actions but firm $i$ 's (so that $A_{-i}=\sum_{j \neq i} a_{i}$ ). Then, a firm's profit function in the aggregative game can be written as $\pi_{i}\left(A_{-i}+a_{i}, a_{i}\right)$. Moreover, we set $\pi_{i}\left(A_{-i}+0,0\right)=0$ and denote $r_{i}\left(A_{-i}\right)$ as the standard best reaction function - so that $r_{i}\left(A_{-i}\right)=\arg \max _{a_{i}} \pi_{i}\left(A, a_{i}\right)$. We assume that $\pi_{i}$ satisfies

$$
(A 1): \partial_{A_{-i}} \pi_{i}\left(A_{-i}+a_{i}, a_{i}\right)<0 \forall a_{i}>0 .
$$

Assumption (A1) means that an increase in the actions of the rivals reduces firm $i$ 's profits. Recall that a firm's action $a_{i}$ varies inversely with its price (as $\psi^{\prime}<0$ ); thus, when other firms increase their action, this amounts to a fall in their prices. (A1) implies that, by raising their own action $a_{i}$, firms impose a negative externality on each other.

We also assume that:

$$
\text { (A2): } \partial_{a_{i} a_{i}}^{2} \pi_{i}\left(A_{-i}+a_{i}, a_{i}\right)<0 \text { at any interior maximum. }
$$

Assumption (A2) is the equivalent of the standard assumption made in Section 2 requiring profit function's concavity. As a direct implication of Assumption (A2), the standard reaction function of firm $i$ to other firms' actions, $r_{i}\left(A_{-i}\right)$, exists, is continuous and solves

$$
\frac{d \pi_{i}\left(A_{-i}+a_{i}, a_{i}\right)}{d a_{i}}=\partial_{A} \pi_{i}\left(A_{-i}+a_{i}, a_{i}\right)+\partial_{a_{i}} \pi_{i}\left(A_{-i}+a_{i}, a_{i}\right)=0
$$


for interior solutions.

Finally, we assume that

$$
\text { (A3): } \partial_{a_{i} a_{i}} \pi_{i}\left(A_{-i}+a_{i}, a_{i}\right)<\partial_{a_{i} A_{-i}} \pi_{i}\left(A_{-i}+a_{i}, a_{i}\right)
$$

which guarantees that reaction functions are well-behaved.

One can verify that these assumptions are satisfied, for instance, for logit, Shubik-Levitan and CES demands if the cost structure exhibits constant returns of scale (e.g., $c(x)=c-x)$ and the investment cost function is quadratic (e.g., $F(x)=x^{2} / 2$ ).

Although we lay out our game as one of price competition, the reformulation of a firm's profit function in (16) implies that, as already discussed above, the firms' choice variables are not necessarily in a relationship of strategic complementarity. Thus, in the aggregative game formulation of our analysis we might have either strategic complementarity, so that $\partial_{a_{i} A_{-i}} \pi_{i}\left(A_{-i}+a_{i}, a_{i}\right)>0$ or strategic substitutability, so that $\partial_{a_{i} A_{-i}} \pi_{i}\left(A_{-i}+a_{i}, a_{i}\right)<0$. In the first case $r_{i}\left(A_{-i}\right)$ is upward sloping. In the second, $r_{i}\left(A_{-i}\right)$ is downward sloping. ${ }^{25}$ We then say that $r_{i}\left(A_{-i}\right)$ takes positive values for all $A_{i} \leq \bar{A}_{-i}$. Instead, $r_{i}\left(A_{-i}\right)=0$ for all $A \geq \bar{A}_{-i}{ }^{26}$

\subsubsection{Construction of the inclusive reaction function}

So far, we have derived the standard reaction function $r_{i}$, as a function of $A_{-i}$. Next, we construct the inclusive reaction function of firm $i$ to the value of the aggregator $A$, which includes its own action $a_{i}$. We will denote it by $\tilde{r}_{i}(A)$. To begin with, we remark some useful properties of $r_{i}\left(A_{-i}\right)$ :

Lemma 5. Assumptions (A2) and (A3) imply that $r^{\prime}\left(A_{-i}\right)>-1$. Then, $A_{-i}+r_{i}\left(A_{-i}\right)$ is strictly increasing in $A_{-i}$.

As a consequence of the monotonicity established in the lemma, with both strategic complementarity and strategic substitutability, the aggregate $A$ defined at the value of the best response of firm $i\left(A_{-i}+r_{i}\left(A_{-i}\right)\right)$ is increasing in $A_{-i}$. We are now in the position to derive the inclusive reaction function $\tilde{r}(A)$.

The monotonicity of $A_{-i}+r_{i}\left(A_{-i}\right)$ implies that we can invert $A_{-i}+r_{i}\left(A_{-i}\right) \equiv h_{i}\left(A_{-i}\right)=A$, to obtain $A_{-i}=h_{i}^{-1}(A) \equiv f_{i}(A)$. Given this, we can write $\tilde{r}_{i}(A) \equiv r_{i}\left(f_{i}(A)\right)$. Lemma 6 follows:

Lemma 6. Assumption (A3) implies that $d \tilde{r}_{i} / d A$ is given by $r_{i}^{\prime} /\left(1+r_{i}^{\prime}\right)<1$. Thus, with strategic complementarity, $r_{i}^{\prime}>0$ implies that the inclusive reaction function is strictly increasing in the aggregate $A$. With strategic substitutability, $r_{i}^{\prime} \in(-1,0)$ means that the inclusive reaction function is strictly decreasing for all $A<\bar{A}_{-i}$.

To conclude this section, we provide a result that will be useful to establish the profitability of the merger. Before doing so, we find it useful to denote by $\bar{\pi}_{i}(A) \equiv \pi_{i}\left(A, \tilde{r}_{i}(A)\right)$ the value of firm $i$ 's profit when it maximizes its profit given the actions of the others and doing so results in an aggregate of value $A$.

\footnotetext{
${ }^{25}$ For instance, in the benchmark, if $c(x)=c-x$ and $F(x)=x^{2} / 2$, then actions will be strategic complement under the logit demand function, strategic substitutes under the Shubik-Levitan demand, and could be either depending on the value of $r$, under the CES demand function.

${ }^{26}$ Intuitively, since the higher $a_{i}$ the more aggressive the action, when rivals are very aggressive, $A_{-i}$ is so large that firm $i$ 's best reply is $a_{i}=0$.
} 
Lemma 7. Under Assumptions (A1)-(A3), $\bar{\pi}(A)$ is strictly decreasing in $A<\bar{A}_{-i}$ and is zero otherwise.

We proceed by characterizing the equilibrium of the aggregative game in the benchmark and with the merger.

\subsubsection{Benchmark with independent firms}

Given the derivation of the inclusive reaction function, we proceed to establish the conditions for the existence of the equilibrium with independent firms. Specifically, an equilibrium exists if it exists a fixed point of the following problem:

$$
\sum_{i=1}^{n} \tilde{r}_{i}(A)=A .
$$

Lemma 8. In the benchmark with $n$ independent firms, an equilibrium $A^{b}$ of the aggregative game always exists. Moreover, the value of $A^{b}$ is unique if, at any fixed point, it holds true that

$$
\sum_{i=1}^{n} \tilde{r}_{i}^{\prime}\left(A^{b}\right)<1 .
$$

Condition (19) is the equivalent of the standard stability condition that we impose in Assumption $(A 4)$ of the main model. It implies that the value of $\sum_{i=1}^{n} \tilde{r}_{i}(A)$ intersects $A$ from above and, given the properties of $\tilde{r}_{i}$, it means that the equilibrium value of $A$ is unique. ${ }^{27}$

\subsubsection{Merger between firm $i$ and firm $k$}

Let firms $i$ and $k$ merge. Merged firms solve

$$
\max _{a_{i}, a_{k}} \pi_{i}\left(A, a_{i}\right)+\pi_{k}\left(A, a_{k}\right) .
$$

Under the assumption that $(A 1)-(A 3)$ are satisfied by the sum of merging firms' profits, the ensuing FOC with respect to $a_{i}$ is sufficient for optimality: ${ }^{28}$

$$
\partial_{A} \pi_{i}\left(A, a_{i}\right)+\partial_{a_{i}} \pi_{i}\left(A, a_{i}\right)+\partial_{A} \pi_{k}\left(A, a_{k}\right)=0 .
$$

In line with the analysis of the main model equilibrium conditions in Section 2.1, the FOC in (21) differs from the benchmark because the merged entity takes into account the impact of changing $a_{i}$ on the profit of firm $k$.

Solving for the FOCs of the insiders, and constructing the respective inclusive best reaction functions, yields $\tilde{r}_{i}^{m}(A)$ and $\tilde{r}_{k}^{m}(A)$, with $\tilde{r}_{i}^{m}(A)+\tilde{r}_{k}^{m}(A) \equiv \tilde{R}^{m}(A)$.

\footnotetext{
${ }^{27}$ Note also that Lemma 8 is the equivalent of Lemma 2 for the aggregative formulation of the game.

${ }^{28}$ The FOC with respect to $a_{k}$ is analogous, thus omitted. Nocke and Schutz (2016) analyze existence and uniqueness of the equilibrium in an aggregative formulation of the oligopolistic pricing game with multi-product firms. They show that these properties apply to the class of demands that we take as leading examples (and in particular, the logit, linear and CES demand systems) under constant returns to scale and no fixed costs; thus, their results do not directly extend to our analysis. We then checked that our assumptions are satisfied by these three demand functions.
} 
Lemma 9. Assume firms $i$ and $k$ merge. Then, for any $A, \tilde{r}_{i}^{m} \leq \tilde{r}_{i}(A)$ and $\tilde{r}_{k}^{m} \leq \tilde{r}_{k}(A)$; thus, $\tilde{r}_{i}(A)+\tilde{r}_{k}(A)>\tilde{R}^{m}(A)$.

For given value of the aggregator $A$, merged firms choose less aggressive actions (i.e., higher prices in our Bertrand game with differentiated products), thus commanding a reduction of respective actions $a_{i}$ and $a_{k}$. Since the merger only affects the inclusive best response functions of the insiders, the equilibrium value of the aggregate under the merger solves the following fixed point problem:

$$
\tilde{\Sigma}^{m}(A) \equiv \sum_{j \neq i, k}^{n} \tilde{r}_{j}(A)+\tilde{R}^{m}(A)=A .
$$

By Lemma 9, the value of $A$ that solves (22), $A^{m}$, is strictly lower than the corresponding value in the benchmark: $A^{m}<A^{b}{ }^{29}$ Moreover, if $d \tilde{\Sigma}^{m}(A) / d A<1$, then $A^{m}$ is unique. All this yields the following result:

Proposition 3. Assume firms $i$ and $k$ merge. The aggregate falls from $A^{b}$ to $A^{m}$. Hence, the sum of the profits of all firms in the industry go up.

With strategic complementarity, the merger is profitable for insiders and outsiders. Indeed, by decreasing the value of the aggregate, the merger raises the profits of insiders ( $\operatorname{since} \tilde{\pi}_{i}(A)$ decreases in $A$ ). Moreover, by strategic complementarity, this makes outsiders' profits increase, too. These results rely on the intuition in Deneckere and Davidson (1985). However, with strategic substitutability, the merger is not necessarily profitable. ${ }^{30}$ All this has implications when we look at specific models: when actions are strategic complements in the aggregative formulation, merger profitability will always be guaranteed, whereas when they are strategic substitutes, we had to check that the merger is profitable.

\subsubsection{Implications for consumer welfare}

We proceed by determining the consequences of the merger for consumer welfare.

Proposition 4. If the demand function satisfies the IIA property, in an industry with $n$ firms, a merger between two firms $i$ and $k$ reduces consumer surplus.

This proposition follows from two considerations. First, by Lemma 9, the equilibrium value of the aggregate under the merger is lower than in the benchmark. Therefore, if consumer welfare depends only on the equilibrium value of the aggregate, showing that the aggregate fall implies that the industry becomes less competitive. Anderson et al. (2016) show that this is the case in Bertrand (pricing) games with differentiated products where demand satisfies the IIA property. ${ }^{31}$ This class of demand functions include the logit and CES demand systems. It does not include linear differentiated products demand systems, like the Shubik and Levitan demand function in (15). This does not necessarily mean that the merger will increase consumer surplus but simply that the sufficient condition in the proposition cannot be applied. In fact, in the parametric analysis developed below, we find that the merger does reduce consumer surplus also in the Shubik-Levitan model whenever the merger turns out to be profitable.

\footnotetext{
${ }^{29}$ Existence is guaranteed by the same arguments as in the proof of Lemma 8 .

${ }^{30}$ See Salant et al. (1983). Recall that in our game even if prices are strategic complements the existence of investments may turn actions in the aggregative formulation of the game into strategic substitutes.

${ }^{31}$ Recall that the IIA property holds true if the ratio of any two demands depends only on their own prices (and is independent of the prices of other options in the choice set).
} 


\subsubsection{Implications for investments}

Proposition 3 shows that, as a consequence of the fall in insiders' actions established in Lemma 9, the aggregate falls with the merger. Thus, if the industry quantity $Q$ increases in the aggregate $A$, the merger reduces the total industry quantity, too. Among others, this property is satisfied by the logit and Shubik-Levitan demand functions. Specifically, for the logit demand system in (14), total quantity $Q$ is given by $A /\left(\exp \left\{s_{0}\right\}+A\right)$, and thus is strictly increasing in the aggregate for any finite value of $s_{0} \cdot{ }^{32}$ Similarly, in the linear products demands à la Shubik and Levitan in (15) one has that $Q=A /(1+2 \gamma)$.

What are the implications of this property for investments? Consider the simple case featuring a constant returns to scale technology $(c(x)=c-x)$ and quadratic investment cost $\left(F(x)=x^{2} / 2\right)$. Then, Lemma 1 implies that $x_{i}=q_{i}$, so that $Q=\sum_{i} x_{i}$, i.e., total investments are equal to $Q$. As a direct consequence, a merger that reduces industry quantity also reduces investments. Next, we prove that this result holds for any admissible function $\chi(\cdot)$.

Proposition 5. If the industry quantity rises with the aggregate $A$, then, in an industry with $n$ symmetric firms, the merger between firms $i$ and $k$ reduces total investments.

This result establishes that a sufficient condition for the merger to reduce total investments is that the fall in the aggregate $A$ implies a reduction in the aggregate demand $Q$ - as is the case for demand functions as logit and Shubik Levitan demand functions. For the CES, the sufficient condition cannot be used as $Q$ does not depend only on $A$. Nonetheless, we note two things: first, the merger will reduce total quantity also with the CES demand function when actions are strategic complements. We will then illustrate by means of specific parametric examples that investments fall with the CES also when actions are strategic substitutes. ${ }^{33}$

\subsubsection{Efficiency gains: $\lambda>0$}

We now consider the case of efficiency gains from the merger. Since the benchmark is the same, we turn directly to the analysis of the merger.

Assume firms $i$ and $k$ merge. In the presence of efficiency gains, the merged firm solves

$$
\max _{a_{i}, a_{k}} \pi_{i}\left(A, a_{i} \mid \lambda\right)+\pi_{k}\left(A, a_{k} \mid \lambda\right)
$$

where

$$
\begin{aligned}
\pi_{i}\left(A, a_{i} \mid \lambda\right)+\pi_{k}\left(A, a_{k} \mid \lambda\right)= & \left(\psi^{-1}\left(a_{i}\right)-c\left(\chi\left(q_{i}\left(A, a_{i}\right) \mid \lambda\right)\right)\right) q_{i}\left(A, a_{i}\right)-F\left(\chi\left(q_{i}\left(A, a_{i}\right) \mid \lambda\right)\right) \\
& +\left(\psi^{-1}\left(a_{k}\right)-c\left(\chi\left(q_{k}\left(A, a_{k}\right) \mid \lambda\right)\right)\right) q_{k}\left(A, a_{k}\right)-F\left(\chi\left(q_{k}\left(A, a_{k}\right) \mid \lambda\right)\right) \\
& +G\left(\chi\left(q_{i}\left(A, a_{i}\right) \mid \lambda\right), \chi\left(q_{k}\left(A, a_{k}\right) \mid \lambda\right)\right),
\end{aligned}
$$

and $x_{i}=\chi\left(q_{i}(\cdot) \mid \lambda\right)$ and $x_{k}=\chi\left(q_{k}(\cdot) \mid \lambda\right)$ are constructed as in the proof of Lemma 3 for the case of $n=2 .{ }^{34}$

\footnotetext{
${ }^{32}$ This demand function is instead constant in the aggregate in the absence of the outside good (i.e., for all $\left.s_{0} \rightarrow-\infty\right)$.

${ }^{33}$ Notably, under linear variable cost and quadratic fixed cost assumptions, for all values of $r$ which make the merger profitable.

${ }^{34}$ The profit function of an outsider firm $j$ is as in (16).
} 
To establish how $\lambda$ affects the equilibrium value of prices and investments, we first review the result in Anderson et al. (2016) that derives the condition under which $r_{i}$ shifts up. Specifically, take the inclusive best response function $r_{i}(\cdot)$ constructed in Lemmas $5-7$ above. Then, consider an exogenous shift in $\lambda$ :

Lemma 10. The inclusive reaction function of the insiders, $r_{i}(A \mid \lambda)$, moves upwards with $\lambda$ : $d r_{i}(A \mid \lambda) / d \lambda>0$.

We then establish the impact of efficiency gains on the aggregate. Specifically, since merged firms solve the problem in (23), the ensuing FOC with respect to $a_{i}$ is:

$$
\partial_{A} \pi_{i}\left(A, a_{i} \mid \lambda\right)+\partial_{a_{i}} \pi_{i}\left(A, a_{i} \mid \lambda\right)+\partial_{A} \pi_{k}\left(A, a_{k} \mid \lambda\right)=0 .
$$

Computing the corresponding inclusive best reaction functions yields $\tilde{r}_{i}^{m}(A \mid \lambda)$ and $\tilde{r}_{k}^{m}(A \mid \lambda)$, with $\tilde{r}_{i}^{m}(A \mid \lambda)+\tilde{r}_{k}^{m}(A \mid \lambda) \equiv \tilde{R}^{m}(A \mid \lambda)>\tilde{R}^{m}(A)$ - where the last result relies on Lemma 9 and 10. The higher the value of the efficiency gain $\lambda$, the more aggressive the actions of the merged entity. In other words, actions $a_{i}$ and $a_{k}$ monotonically increase with $\lambda$.

Given $\tilde{R}^{m}(A \mid \lambda)>\tilde{R}^{m}(A)$, the ensuing equilibrium value of the aggregate with efficiency gains is larger than in the case with $\lambda=0$. Specifically, since firms solve:

$$
\Sigma^{m}(A \mid \lambda) \equiv \sum_{j \neq i, k}^{n} \tilde{r}_{j}(A)+\tilde{R}^{m}(A \mid \lambda)=A,
$$

the value of $A$ that solves (24), $A_{\lambda}^{m}$, is strictly larger than the corresponding value without efficiency gains: $A^{m}<A_{\lambda}^{m}$. Existence of $A_{\lambda}^{m}$ follows from the same arguments as in the proof of Lemma 8 and, if $d \tilde{\Sigma}^{m}(A \mid \lambda) / d A<1, A_{\lambda}^{m}$ is unique.

We conclude by establishing the uniqueness of the value of $\lambda$ that renders the merger welfare neutral with respect to the merger.

Lemma 11. Assume firms $i$ and $k$ merge. Then, there exists a unique value of $\lambda$ such that $A^{m}(\tilde{\lambda})=A^{b}$, with $A^{m}(\tilde{\lambda})<A^{b}$ for all $\lambda<\tilde{\lambda}$ and $A^{m}(\tilde{\lambda}) \geq A^{b}$ otherwise.

Conclusions of the case with efficiency gains We can now draw on the analysis made for the case where $\lambda=0$ to conclude the analysis of the merger with efficiency gains. In particular, we know that - under the assumption that the IIA property holds - the effects on the consumer surplus depend on whether the aggregate $A$ increases or not with the merger.

Proposition 6. Assume firms $i$ and $k$ merge. If efficiency gains are small enough $(\lambda<\tilde{\lambda})$, the merger reduces consumer surplus. Otherwise $(\lambda \geq \tilde{\lambda})$, it will be (weakly) pro-competitive.

\subsection{Specific functional forms models}

In this section, we first use the Shubik and Levitan model to illustrate the functioning of the aggregative formulation. We then resort to parametric models to get some further insights on the effects of the merger on some variables of interest. 


\subsubsection{Aggregative analysis with linear demand}

In this section, we solve the linear demand example to illustrate the construction of the inclusive best response function and the derivation of the equilibrium value of the aggregate. We will do this for the benchmark, and provide a graphical illustration of how the merger changes the aggregate in equilibrium.

Consider the Shubik-Levitan linear demand function. Its aggregative formulation is given by

$$
q_{i}\left(A, a_{i}\right)=\frac{a_{i}[1+(n-1) \gamma]-\gamma\left(a_{i}+A_{-i}\right)}{(1-\gamma)[1+(n-1) \gamma]} .
$$

Assume also that $c(x)=c-x$ and $F(x)=x^{2} / 2$, so that $x_{i}=\chi\left(q_{i}\left(A, a_{i}\right)\right)=q_{i}\left(A, a_{i}\right){ }^{35}$

First, we find $r_{i}\left(A_{-i}\right)$ by solving $d \pi\left(r\left(A_{-i}\right)+A_{-i}, r\left(A_{-i}\right)\right) / d a_{i}=0$ for $r\left(A_{-i}\right)$. Let us define $B \equiv[1+(n-1) \gamma]$. We obtain the following expression:

$$
r_{i}\left(A_{-i}\right)=\frac{\gamma^{2} A_{-i}(1-B)+B(\alpha-1)(1-\gamma)(B-\gamma)}{2 B \gamma^{2}-\gamma^{2}+B^{2}(1-2 \gamma)} .
$$

We then invert $A_{-i}+r_{i}\left(A_{-i}\right)=A$, to get $A_{-i}=f_{i}(A)$. Specifically,

$$
f_{i}(A)=\frac{A \gamma-B[(\alpha-1)(1-\gamma)-A(1-2 \gamma)]}{B\left(B-2 B \gamma+\gamma^{2}\right)}(B-\gamma) .
$$

Inserting this $f_{i}(A)$ into $r_{i}\left(A_{-i}\right)$, we obtain the inclusive best reaction function: $\tilde{r}_{i}(A) \equiv$ $r_{i}\left(f_{i}(A)\right)$. In our symmetric Shubik-Levitan linear demand system, $\tilde{r}_{i}(A)=\tilde{r}(A)$ for all $i$ :

$$
\tilde{r}(A)=\frac{\gamma^{2} A(1-B)+B(\alpha-1)(1-\gamma)(B-\gamma)}{B\left(B-2 B \gamma+\gamma^{2}\right)} .
$$

To find the equilibrium value of the aggregate $A$ in the benchmark, we then solve $n \tilde{r}_{i}(A)=A$ and find that

$$
A=A^{b} \equiv \frac{(\alpha-1) B(B-\gamma)(1-\gamma) n}{B^{2}(1-2 \gamma)-\gamma^{2} n+B \gamma^{2}(1+n)} .
$$

This $A^{b}$ is unique by $(A 2)-(A 3)$ and $n \tilde{r}_{i}^{\prime}(A)<1$. Specifically, in the benchmark,

$$
\begin{array}{ll}
\text { (A2): } & B^{2}(\gamma-B)[B(1-2 \gamma)+\gamma]<0, \\
\text { (A3): } & B\left(B-2 \gamma B+\gamma^{2}\right)>0,
\end{array}
$$

and are both satisfied for all $\gamma \in(0, \bar{\gamma})$, with $\bar{\gamma} \equiv\left(n-3+\sqrt{n^{2}+2 n-3}\right) / 2(2 n-3)$.

With the merger, the insiders' inclusive reaction function is ${ }^{36}$

$$
\tilde{r}^{m}(A)=\frac{B \gamma[2-2 \alpha(1-\gamma)-(2+A) \gamma]+(\alpha-1) B^{2}(1-\gamma)}{B\left(B-2 B \gamma+2 \gamma^{2}\right)} .
$$

\footnotetext{
${ }^{35}$ Recall that $a_{i}=\alpha-p_{i}$ and $A_{-i}=\sum_{j \neq i} a_{j}$.

${ }^{36}$ We do not report the calculations for the derivation of $\tilde{r}^{m}$ because we followed the same procedure as in the benchmark.
} 
To find the equilibrium value of the aggregate, we then solve $2 \tilde{r}^{m}(A)+(n-2) \tilde{r}(A)=A$, where $\tilde{r}(A)$, the inclusive best reaction function of the outsiders, is as in (25). The unique solution of this fixed point problem is

$$
A=A^{m} \equiv \frac{(\alpha-1) B(1-\gamma)\left\{2 \gamma^{3} n-B^{2}(1-2 \gamma) n+B \gamma[2+n-2 \gamma(1+2 n)]\right\}}{B(1-2 \gamma)\left[2 \gamma^{2}-3 B \gamma^{2}-B^{2}(1-2 \gamma)\right]-(B-1) \gamma^{2}\left(B-2 B \gamma+2 \gamma^{2}\right) n} .
$$

With the merger, assumptions (A2) and (A3) hold true if

$$
\begin{array}{ll}
\text { (A2): } & (B-2 \gamma)[2(B-1) \gamma-B]<0, \\
\text { (A3): } & \gamma^{2}(2-3 B)-B^{2}(1-2 \gamma)<0 .
\end{array}
$$

These conditions are again satisfied for all the positive values of $\gamma$ below $\bar{\gamma}$. Moreover, confirming the result in Proposition $3, A^{m}<A^{b}$ for all $\gamma \in(0, \bar{\gamma})$.

In line with these findings, Figure 1 shows that the aggregate is smaller with the merger for $\gamma=0.4$ and $n=3$. While the reduction in the aggregate is a sufficient condition for consumer welfare to fall with demand functions like CES or logit, it is not with the ShubikLevitan demand model. The reason is that the latter does not satisfy the IIA. Hence, in what follows, we look at how the merger changes consumer surplus with respect to the benchmark. Before going there, though, we provide a graphical illustration of the conditions under which assumptions (A2) and (A3) are satisfied in the model with linear demand, and the merger's profitability condition.

Figure 1: Benchmark and merger - Aggregative analysis with linear demand

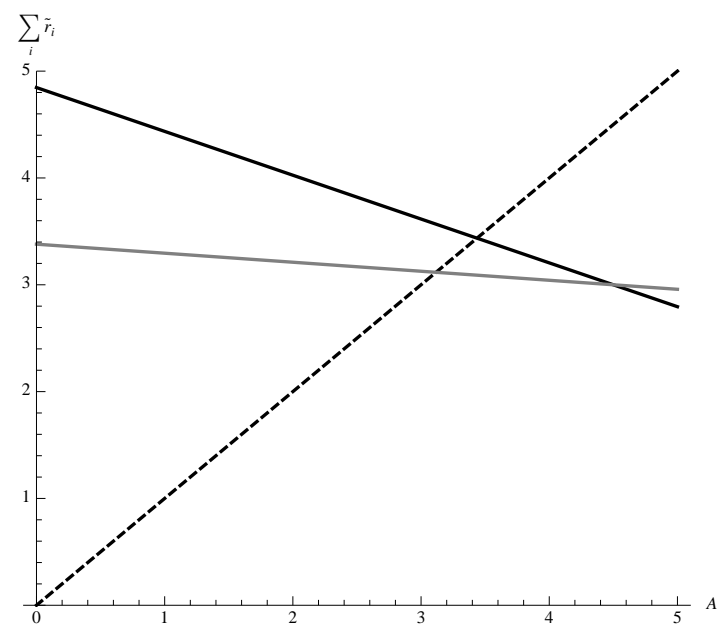

Note: the dashed line corresponds to the $45^{\circ}$ line, the black line is the sum of inclusive reaction functions in the benchmark, the grey line is the sum of inclusive reaction functions with the merger. The parametric values we use are $\alpha=2, c=1$ and $\gamma=0.4$. As we show in Figure 2, right panel, the merger is profitable and anticompetitive when $n=3$ and $\gamma=0.4$ for any $\alpha>c$.

In Figure 2, left panel, we illustrate two things: first, the condition implied by $(A 3)$ is more binding than the one coming from (A2) in both the benchmark and the merger. Second, the condition for (A3) in the benchmark implies the other three. In particular, the solid black line corresponds to the maximum values below this assumption is satisfied, $\bar{\gamma}$. 
Figure 2: Assumptions, consumer welfare, and profitability
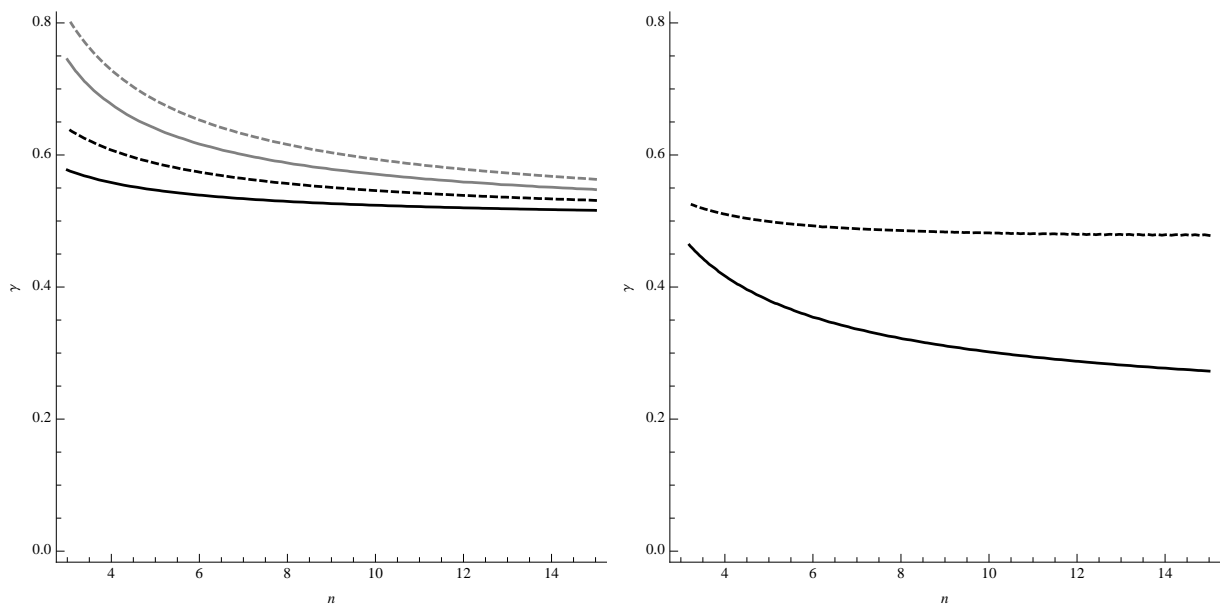

Note: in the left panel, the solid black (respectively, grey) line corresponds to the maximum value of $\gamma$ such that assumption (A3) holds in the benchmark (respectively, merger). The black (respectively, grey) dashed line gives the maximum value of $\gamma$ such that assumption (A2) is satisfied in the benchmark (respectively, merger). In the right panel, the solid line gives the maximum value of $\gamma$ below which the merger is profitable, while the dashed line gives the maximum value of $\gamma$ below which the merger implies a fall in consumer surplus.

We now discuss the conditions for the merger to be profitable and its impact on welfare. In the right panel of Figure 2, we plot two curves: the solid one gives the maximum values of $\gamma$ such that the merger is profitable, the dashed ones those below which it reduces consumer welfare. This figure prompts two considerations. First, the profitability condition is more binding than all the parametric assumptions (plotted in the left panel). Second, it shows that the merger is anticompetitive whenever it is profitable.

Figure 3: Consumer surplus difference

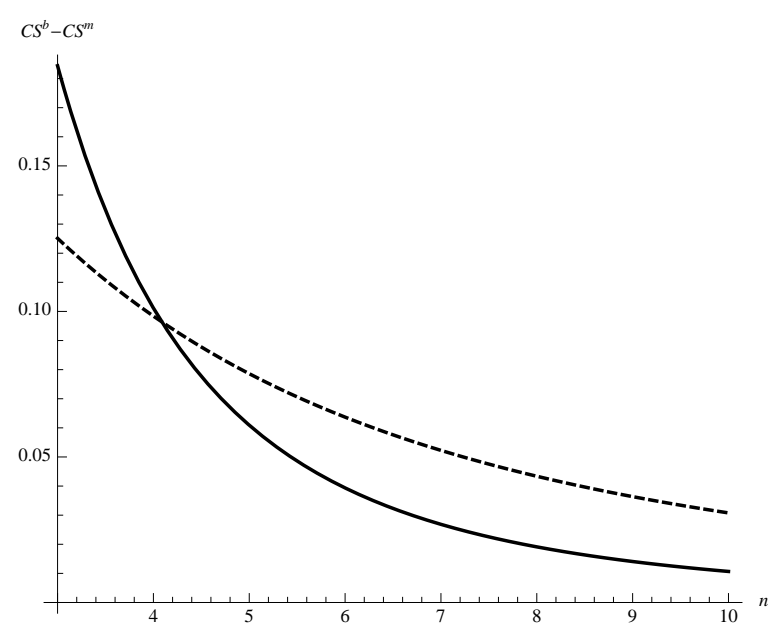

Note: the solid line plots the consumer surplus difference when $\gamma=0.3$, the dashed line when $\gamma=0.1$. The merger is profitable in both cases for all $n \leq 10$.

To conclude, we look at how the loss in consumer surplus caused by the merger $\left(C S^{b}-C S^{m}\right)$ evolves with the number of firms, $n$. It can be showed that as $n$ grows, consumer loss shrinks. (Figure 3 illustrates this result for different values of $\gamma$.) This confirms in a setting where firms choose both investment and price what we know from standard merger theory, namely that 
the harm caused by a merger is - ceteris paribus - the more sizable the more concentrated the industry. If antitrust authorities could prohibit only mergers which create "significant lessening of competition" then they might limit their attention to mergers taking place in more concentrated markets.

\subsubsection{Parametric analysis}

We have seen above that, absent efficiency gains, the merger leads to lower consumer surplus for a class of models that we can write as aggregative games and satisfy the IIA property. However, some models which are commonly used in industrial organization do not belong to that class. Furthermore, dealing with closed-form solutions will also allow us to illustrate the impact of the merger on all variables, thereby gaining further insight on merger effects.

In this section, therefore, we report parametric results for the study of the merger effects for a model that does not satisfy the aggregative games properties, the Salop circle model, as well as for models which can be written as aggregative games - namely the CES, logit and Shubik-Levitan demand functions.

We restrict attention to $n=3$ symmetric firms in the industry, the minimum number which allows us to analyze the effects of the merger on insiders and outsiders (by looking at more than three firms would complicate calculations without adding any additional insight). We assume that marginal costs of production are linear, $c\left(x_{i}\right)=1-x_{i}$, that fixed costs are quadratic, $F\left(x_{i}\right)=x_{i}^{2} / 2$, and (for the moment) that efficiency gains are absent, $\lambda=0 .{ }^{37}$ Note that given these assumptions, the FOCs with respect to investments, $\partial_{x_{i}} c\left(x_{i}\right) q_{i}\left(p_{i}, p_{-i}\right)-\partial_{x_{i}} F\left(x_{i}\right)=0$ simplify to $q_{i}\left(p_{i}, p_{-i}\right)=x_{i}$, entailing the equivalence between outputs and investment levels at all the equilibria.

Table 1 illustrates the results with particular parameter values. While we could obtain analytical solutions for the Shubik-Levitan and the Salop models, we could not find closedform solutions with the CES and logit demand functions in the merger case (which entails asymmetries). Thus, we report results for representative values of the parameters.

\footnotetext{
${ }^{37}$ See Section 3.5 below for a numerical computation of this model with efficiency gains, where we compare the merger with the benchmark and a Research Joint Venture.
} 
Table 1: Equilibrium outcomes with simultaneous moves

\begin{tabular}{l|c|c|c|c|c|c|c}
\hline \hline & Shubik-Levitan & \multicolumn{2}{|c|}{ Salop } & \multicolumn{2}{c|}{ CES } & \multicolumn{2}{c}{ Logit } \\
\hline & $a=2, \gamma=0.3$ & $t=0.9$ & $t=1.8$ & $r=1$ & $r=1.6$ & $s_{0} \rightarrow-\infty$ & $s_{0}=0$ \\
\hline \hline$p^{b}$ & 0.91 & 0.97 & 1.27 & 2.11 & 1.51 & 2.17 & 2.01 \\
$p_{I}^{m}$ & 1.06 & 1.17 & 1.67 & 3.10 & 2.06 & 2.91 & 2.12 \\
$p_{O}^{m}$ & 0.89 & 0.94 & 1.39 & 2.19 & 1.49 & 2.39 & 2.01 \\
$x^{b}=q^{b}$ & 0.68 & 0.33 & 0.33 & 0.16 & 0.22 & 0.33 & 0.096 \\
$x_{I}^{m}=q_{I}^{m}$ & 0.54 & 0.21 & 0.26 & 0.09 & 0.13 & 0.27 & 0.087 \\
$x_{O}^{m}=q_{O}^{m}$ & 0.79 & 0.58 & 0.49 & 0.19 & 0.31 & 0.46 & 0.097 \\
$\pi^{b}$ & 0.17 & 0.04 & 0.14 & 0.19 & 0.137 & 0.44 & 0.101 \\
$\pi_{I}^{m}+\pi_{I}^{m}$ & 0.36 & 0.11 & 0.41 & 0.41 & 0.298 & 1.11 & 0.2 \\
$\pi_{O}^{m}$ & 0.22 & 0.14 & 0.31 & 0.24 & 0.197 & 0.74 & 0.103 \\
$C S^{m}-C S^{b}$ & -0.18 & -0.10 & -0.387 & -0.24 & -0.17 & -0.54 & -0.021 \\
$W^{m}-W^{b}$ & -0.09 & 0.02 & -0.004 & -0.15 & -0.08 & -0.24 & -0.017 \\
\hline \hline
\end{tabular}

Note: with the merger, we denote an insider firm by $I$ and an outsider firm by $O$. The Shubik-Levitan demand function is defined in (15). For the Salop location model, we assume a linear transportation cost $t$ and a circle of unit length. The CES demand function is given by $q_{i}=p_{i}^{-1-r} / \sum p_{i}^{-r}$. For values $r>1.6$ the merger is not profitable. Finally, the logit demand model is defined in (14). We use $\mu=1$, and distinguish between $s_{0} \rightarrow-\infty \Longleftrightarrow \exp \left\{s_{0}\right\}=0$, which corresponds to the case without outside good, and $s_{0}=0$, which corresponds to the widely employed case in which $\exp \left\{s_{0}\right\}=1$.

Description and interpretation of the results. In all the models analyzed it turns out that the merger will harm consumers. This is mainly due to the insiders' lower investments and higher prices. In some cases, outsiders' prices may decrease with the merger (due to their higher investments) but in none of the cases analyzed to such an extent as to lead to a pro-competitive effect.

To understand these results, we can refer to the mechanisms we have already stressed in this section. When two firms merge, we know from the analysis of their price FOCs that they will raise prices relative to the benchmark. Given investments, the outsider will also tend to raise prices, but by less than the insiders. As a result, the quantity of the insiders fall and that of the outsider increases. From the investment FOCs we know that firms' investments increase with the quantity sold: hence, insiders' investments fall (their costs will then rise) and the outsider's investment rises (its production cost will fall), but total investments decrease. While the investment effect reinforces the rise in the price of the insiders, it moves in the opposite direction for the outsider, as the larger investment lowers its production costs and tends to decrease its price. At the merger equilibrium, the price of the outsider may increase or decrease relative to the benchmark. Indeed, the table above reports cases where the merger decreases the outsider's price. ${ }^{38}$

It is also worth stressing that in all models we have studied the merger always decreases consumer surplus. Note that the merger always increases outsiders' profits (they benefit from the insiders' higher prices and lower investments) and that we make assumptions aimed at

\footnotetext{
${ }^{38}$ These results also show that, in the aggregative formulation of our game, strategic complementarity holds under the logit demand function and under the CES function for low enough values of $r$, e.g. for $r=1$. With the Shubik-Levitan demand, or CES demand with, e.g., $r=1.6$, the firms' actions are strategic substitutes, implying that the merger increases insiders' prices but lowers outsiders'. However, the fall in the actions of the insiders is never outweighed by the increase in the actions of the outsiders.
} 
guaranteeing that the merger is profitable for the insiders. ${ }^{39}$ In principle the merger may raise total surplus, and we do find that this may happen in the Salop model. Before making too much of this result, though, consider that in the Salop model demand is completely inelastic (all the market is covered and each consumer buys just one unit), hence there will be no dead-weight loss from the merger's higher prices.

Efficiency gains $(\lambda>0)$ We have carried out an analysis of the Shubik-Levitan and Salop circle model (which do not satisfy the IIA property) under the assumption of efficiency gains, and it confirms the results obtained above in Subsection 2.3.7: while at the benchmark the equilibrium variables are not affected by the level of efficiency gains $\lambda$, as $\lambda$ increases the 'performance' of the merger becomes better and better (total investments increase and consumer surplus increases) until the merger becomes beneficial to consumers. In Section 3.5 below, we shall report a graphical analysis which illustrates these findings.

\section{Extensions}

In this section, we study a few extensions of our main model. First, we relax the assumption that firms' products are symmetric. Second, we consider quality-enhancing investments rather than cost-reducing investments. Third, we consider a sequential first-investments-thenprice game rather than a simultaneous move game. Fourth, we consider the possibility that firms cannot perfectly appropriate their investments (involuntary spillovers). Finally, we study market allocations and investments with a NSA/RJV.

\subsection{Asymmetric products}

The model has been solved under the assumption of symmetric goods. In this section, we discuss the robustness of the results in Propositions 3, 4 and 5 when relaxing this condition. ${ }^{40}$

First of all, notice that nothing in the aggregative formulation of the model requires symmetry among the firms in the industry (indeed, the advantage of this approach is that it relies on the aggregate of the actions, rather than its composition). Hence the derivation of the benchmark equilibrium does not rely on an assumption of symmetry.

Next, consider the merger. The outsiders' inclusive reaction functions are not affected by the merger, and are the same as in the benchmark. As for the insiders, when we showed that the merger reduces the value of their inclusive reaction functions (Lemma 9), symmetry allowed us to rule out the case in which the new firm treats the two products differently. Consider now the case in which the insiders' products may be asymmetric. If the merged entity keeps both goods active, then the proof proceeds as in Lemma 9, which means that both inclusive

\footnotetext{
${ }^{39}$ Notably, as substitutability among the products increases, competition becomes fiercer and the insiders will lose more from being less efficient than outsiders (due to lower investments under the merger). Therefore, a common restriction in the models is that products are sufficiently differentiated: this translates into assuming a low enough $\gamma$ in the Shubik-Levitan model, a large enough $t$ in the Salop model, and a low enough $r$ in the CES model.

${ }^{40}$ Alternatively, one might consider a setting in which firms offer asymmetric product portfolios. While we do not expect the results of the analysis to differ from a qualitative point of view, the challenging feature of such an asymmetric model is that, based on the scant available literature on multi-product firms, it would be complicated to establish existence and uniqueness of the equilibrium with and without the merger.
} 
best reply functions fall with respect to the benchmark. If instead the merged entity closes down firm $i$ 's good, then $\tilde{r}_{i}^{m}(A)=0<\tilde{r}_{i}(A)$. Hence, $\tilde{r}_{k}^{m}(A)=\tilde{r}_{k}(A)$. This means that $\tilde{R}^{m}<\tilde{r}_{i}(A)+\tilde{r}_{k}(A)$ and the merger reduces the aggregate as it was the case with symmetric products (i.e., $A^{b}<A^{m}$ ).

What are the implications for consumer surplus? As argued after Proposition 4, a sufficient condition for the merger to reduce consumer welfare is that the demand satisfies the IIA property (or, equivalently, that the consumer surplus only depends on the aggregate, not on its composition). Thus, with and without symmetry, the same condition is sufficient to show that the merger is anticompetitive.

As far as total industry investment is concerned, the analysis in Proposition 5 proves the fall in investments under the condition that total demand depends on the aggregate. Symmetry allows us to streamline the comparison between the value of investments before and after the merger, and then show that investments fall for any (weakly) concave investment function $\chi$.

With asymmetric products the comparison is complicated by the fact that outsiders' rise in investments might more than compensate the fall in insiders', even if total demand falls. However, we obtain the same result as in the proposition if the investment function is linear in $x$, e.g., $q=\zeta x$, with $\zeta>0$ - which holds true whenever $-F^{\prime}\left(x_{i}\right) / c^{\prime}\left(x_{i}\right)=\zeta x_{i}$ (see the proof of Lemma 1 for details). Then, $\zeta \sum_{i} x_{i}=\sum_{i} q_{i}$ and a merger that reduces industry quantity decreases industry investments, too.

Finally, in the model with efficiency gains (Section 2.3.7), we use symmetry to simplify the derivation of the investment function $x_{i}=\chi\left(q_{i} \mid \lambda\right)$. However, it is possible to operate our transformation and solve the "price-only" model (and the aggregative version of it) even with asymmetric firms. In that case, the investment function is obtained solving the FOCs for $x_{i}$ and $x_{k}$ as function of $q_{i}$ and $q_{k}$. Hence, symmetry is not necessary to derive the results, although admittedly it greatly simplifies the analysis.

\subsection{Quality-increasing investments}

In this section, we discuss the implications of a model in which the investments carried out by firms increase the quality of their good, rather than decreasing their cost of production. Specifically, we let the quantity of a firm depend on its own and rivals' prices $(p)$ and quality (x) level: $q_{i}=q_{i}\left(p_{i}, \bar{p}_{-i}, x_{i}, \bar{x}_{-i}\right)$, with $\partial_{x_{i}} q_{i} \geq 0$ and $\partial_{x_{i}} q_{k} \leq 0$ (that is, an increase in the quality of firm $i$ implies that $q_{i}$ rises and $q_{k}$ reduces, with $i \neq k$, as standard in models of quality differentiation). Consider further the case where the price- and quality-setting stages take place simultaneously, the investment in quality does not generate any efficiency gains and each firm bears a marginal cost of production equal to $c$.

If firms act independently, each solves the following maximization problem:

$$
\max _{p_{i}, x_{i}} \hat{\pi}_{i}\left(p_{i}, \bar{p}_{-i}, x_{i}, \bar{x}_{-i}\right)=q_{i}\left(p_{i}, \bar{p}_{-i}, x_{i}, \bar{x}_{-i}\right)\left(p_{i}-c\right)-F\left(x_{i}\right), i=1, \ldots, n .
$$

The associated FOCs are:

$$
\begin{aligned}
\partial_{p_{i}} \hat{\pi}_{i} & =q_{i}\left(p_{i}, \bar{p}_{-i}, x_{i}, \bar{x}_{-i}\right)+\partial_{p_{i}} q_{i}\left(p_{i}, \bar{p}_{-i}, x_{i}, \bar{x}_{-i}\right)\left(p_{i}-c\right)=0, \\
\partial_{x_{i}} \hat{\pi}_{i} & =\partial_{x_{i}} q_{i}\left(p_{i}, \bar{p}_{-i}, x_{i}, \bar{x}_{-i}\right)\left(p_{i}-c\right)-F^{\prime}\left(x_{i}\right)=0 .
\end{aligned}
$$

If firms $i$ and $k$ merge, they maximize $\hat{\pi}_{i, k} \equiv \hat{\pi}_{i}\left(p_{i}, \bar{p}_{-i}, x_{i}, \bar{x}_{-i}\right)+\hat{\pi}_{k}\left(p_{k}, \bar{p}_{-k}, x_{k}, \bar{x}_{-k}\right)$ with respect to $p_{i}, p_{k}, x_{i}$ and $x_{k}$, with $i, k=1, \ldots, n$, and $i \neq k$. The FOCs with respect to $p_{i}$ and 
$x_{i}$ follow (we omit those for $p_{k}$ and $x_{k}$, which are symmetric, and those of the outsiders, which are the same as in the benchmark):

$$
\begin{aligned}
& \partial_{p_{i}} \hat{\pi}_{i, k}=q_{i}\left(p_{i}, \bar{p}_{-i}, x_{i}, \bar{x}_{-i}\right)+\partial_{p_{i}} q_{i}\left(p_{i}, \bar{p}_{-i}, x_{i}, \bar{x}_{-i}\right)\left(p_{i}-c\right) \\
& +\partial_{p_{i}} q_{k}\left(p_{k}, \bar{p}_{-k}, x_{k}, \bar{x}_{-k}\right)\left(p_{k}-c\right)=0, \\
& \partial_{x_{i}} \hat{\pi}_{i, k}=\partial_{x_{i}} q_{i}\left(p_{i}, \bar{p}_{-i}, x_{i}, \bar{x}_{-i}\right)\left(p_{i}-c\right) \\
& +\partial_{x_{i}} q_{k}\left(p_{k}, \bar{p}_{-k}, x_{k}, \bar{x}_{-k}\right)\left(p_{k}-c\right)-F^{\prime}\left(x_{i}\right)=0 .
\end{aligned}
$$

When investments increase a firm's quality, the impact of the merger is a priori ambiguous. Compare first the insiders' FOCs with respect to prices, (26) and (28): under the merger there is the usual internalization of price effects which - ceteris paribus - leads the merged entity to raise prices. This will increase the marginal revenue from investing and will therefore tend to increase the insiders' incentive to invest. On the other hand, by comparing the investment FOCs of the insiders, (27) and (29), it turns out that the merged entity will have a lower incentive to invest: this is because it internalizes the fact that any extra dollar of investments on product $i$ will lower the demand of product $k$, which also belongs to the same firm. It is therefore difficult to say whether insiders' investments will increase or decrease with the merger.

As for the outsiders, their FOCs are not affected by the merger, but because of strategic complementarity, outsiders' prices would tend to rise, which in turn raises their incentives to invest. But of course the change in the insiders' investments will also affect their FOCs, so it is difficult to reach an unambiguous conclusion about the effect of the merger on the outsiders too.

\subsubsection{Cost-reducing and quality-increasing: indifference results}

Given the ambiguous conclusions of the general model with quality-increasing investment, we show two formulations of the demand model under which the equilibrium results of the game with cost-reducing investments are equivalent to those with quality-increasing investments.

Quality-adjusted model, and CES demand In our main model, the utility of the representative consumer takes the following form $U\left(q_{1}, \ldots, q_{n}\right)$. Assume now that the consumer's utility depends on $x_{i} q_{i}$. That is, $U\left(x_{1} q_{1}, \ldots, x_{n} q_{n}\right)$. In this alternative model, the solution of the utility maximization problem leads to a demand system as in $x_{i} q_{i}=D_{i}\left(z_{i}, \bar{z}_{-i}\right)$, with $z_{i}=p_{i} / x_{i}$ and $i=1, . ., n$.

In this context, the gross profits of a firm $i$ is equivalent to the gross profits in our baseline model when considering a quality adjusted value of marginal costs of production $\left(c / x_{i}\right)$ :

$$
\begin{aligned}
\hat{\pi}_{i}+F\left(x_{i}\right) & =\left(p_{i}-c\right) q_{i} \\
& =\left(z_{i}-c / x_{i}\right) D_{i}\left(z_{i}, \bar{z}_{-i}\right) .
\end{aligned}
$$

This equivalence means that all the conclusions derived in the model with cost-reducing investment extend to this model with quality-adjusted prices and investments. ${ }^{41}$ It also extends to any model where demand can be written as a function of the price-investment ratio, as is the case, for instance, of the vertical product differentiation version of the CES $\left(q_{i}=\left(p_{i} / x_{i}\right)^{(r-1)} / \sum_{j=1}^{n}\left(p_{j} / x_{j}\right)^{r}\right)$.

\footnotetext{
${ }^{41}$ A model which presents this feature is the one used by Sutton (1998:58ff) and later used by, e.g., Symeonidis (2003).
} 
Hedonic price transformation We now show that there exists another class of demand models for which we can establish an equivalence between the results with cost-reducing and quality-increasing investments.

Assume that $q_{i}\left(p_{i}, \bar{p}_{-i}, x_{i}, \bar{x}_{-i}\right)$ can be written as $q_{i}\left(p_{i}-v\left(x_{i}\right), \bar{p}_{-i}-v\left(\bar{x}_{-i}\right)\right)$, where $q_{i}$ is decreasing in $\left(p_{i}-v\left(x_{i}\right)\right)$ and increasing in the elements of the vector $\bar{p}_{-i}-v\left(\bar{x}_{-i}\right)$, and where $v\left(x_{j}\right)$ increases in the investment $x_{j}$ for all $j$. This describes a model with quality-enhancing investments (the higher $x_{i}$ the higher the perceived quality, and hence the demand for product i) where each firm has profit

$$
\pi_{i}\left(p_{i}, \bar{p}_{-i}, x_{i}, \bar{x}_{-i}\right)=\left(p_{i}-c\right) q_{i}\left(p_{i}-v\left(x_{i}\right), \bar{p}_{-i}-v\left(\bar{x}_{-i}\right)\right)-F\left(x_{i}\right) .
$$

If one defines $h_{i} \equiv p_{i}-v\left(x_{i}\right)$ as the hedonic price of the quality determined by $x_{i}$, then the profit function above is equivalent to:

$$
\pi_{i}\left(h_{i}, \bar{h}_{-i}, x_{i}, \bar{x}_{-i}\right)=\left(h_{i}-\left(c-v\left(x_{i}\right)\right)\right) q_{i}\left(h_{i}, \bar{h}_{-i}\right)-F\left(x_{i}\right),
$$

which is nothing else than the profit function of a firm $i$ whose investment reduces its marginal cost according to $c_{i}\left(x_{i}\right)=c-v\left(x_{i}\right)$. This is like in the cost-reducing model we dealt with in the previous section.

For instance, let us study a quality-enhancing version of the model by using a logit demand function. In its vertical product differentiation version, this demand can be written as:

$$
q_{i}=\frac{\exp \left\{\left(s+v\left(x_{i}\right)-p_{i}\right)\right\}}{\exp \left\{\left(s_{0}-p_{0}\right)\right\}+\sum_{j=1}^{n} \exp \left\{\left(s+v\left(x_{j}\right)-p_{j}\right)\right\}},
$$

where 0 is the outside good, and each firm $i$ has profit $\pi_{i}=\left(p_{i}-c\right) q_{i}(\cdot, \cdot)-F\left(x_{i}\right)$. By defining the hedonic price $h_{i}=p_{i}-v\left(x_{i}\right)$, the profit can be rewritten as: $\pi_{i}=\left(h_{i}-c+v\left(x_{i}\right)\right)(\exp \{(s-$ $\left.\left.\left.h_{i}\right)\right\}\right) /\left(\exp \left\{\left(s_{0}-p_{0}\right)\right\}+\sum_{j=1}^{n} \exp \left\{\left(s-h_{j}\right)\right\}\right)-F\left(x_{i}\right)$, which is a version of the cost-reducing model we analyzed above. Not only the logit demand falls within this class of functions, but also the Shubik-Levitan demand system (see Häckner, 2000) of the type $q_{i}=\left(\alpha_{i}-p_{i}\right) \beta-\gamma \sum_{j}\left(\alpha_{j}-p_{j}\right)$, with $\alpha_{i}=\alpha+\alpha\left(x_{i}\right)$ measuring quality, $\beta>0$ and $\gamma \in(0,1)$. Specifically, this would be equivalent to studying a model of cost-reducing investments $c_{i}=c-c\left(x_{i}\right)$ with a demand $q_{i}=\left(\alpha-p_{i}\right) \beta-\gamma \sum_{j}\left(\alpha-p_{j}\right)$

In sum, some standard models where firms invest to enhance their quality can be reinterpreted as the cost-reducing models we have studied in the previous sections. Hence, the same conclusions would apply: a merger is anti-competitive unless it entails sufficient efficiency gains. $^{42}$

\subsection{The merger with involuntary spillovers}

We have so far assumed that firms can fully appropriate their investments or innovations. While this is a realistic assumption for many industries where physical or intellectual property rights are typically well protected (think for instance of MNOs' investments in telephone infrastructure, or a pharmaceutical company's new molecule), there may be industries where involuntary

\footnotetext{
${ }^{42}$ Perhaps the most popular model of vertical product differentiation is the Shaked and Sutton model. In the previous version of the paper we showed that even in that model (in which firms set sequentially qualities and then prices) the merger decreases investments and consumer surplus.
} 
spillovers are substantial, due to e.g. imitation, or movement of research personnel among firms. In this section, we show that involuntary spillovers have the same qualitative effect as the efficiency gains in our analysis. In order to make the treatment of spillovers as close as possible to the existing literature (see, e.g., d'Aspremont and Jacquemin, 1988) we assume that - in case of spillovers - the investment by a firm decreases the marginal cost of production of a rival. We then solve our model under the assumptions that $n=2, F\left(x_{i}\right)=x_{i}^{2} / 2$ and $c\left(x_{i}, x_{k}\right)=c-x_{i}-\sigma x_{k}$, where $\sigma \in[0,1]$ represents involuntary spillovers. We first consider the benchmark, and then the merger.

At the benchmark, firm $i$ 's problem is: $\max _{p_{i}, x_{i}} \pi_{i}^{i n v}=\left[p_{i}-c+x_{i}+\sigma x_{k}\right] q_{i}\left(p_{i}, p_{k}\right)-x_{i}^{2} / 2$, for $i, j=1,2 ; i \neq j$. Solving the FOC with respect to the investment gives: $x_{i}=q_{i}\left(p_{i}, p_{k}\right)$, and, after replacement, firm $i$ 's problem is in one variable only:

$$
\max _{p_{i}} \pi_{i}^{i n v}=\left[p_{i}-c+\sigma q_{k}\left(p_{i}, p_{k}\right)\right] q_{i}\left(p_{i}, p_{k}\right)+\frac{\left(q_{i}\left(p_{i}, p_{k}\right)\right)^{2}}{2},
$$

subject to $x_{i}=q_{i}\left(p_{i}, p_{k}\right)$. The FOCs are given by:

$$
\begin{aligned}
\partial_{p_{i}} \pi_{i}^{i n v}=q_{i}\left(p_{i}, p_{k}\right)+\left(p_{i}-c\right) \partial_{p_{i}} q_{i}\left(p_{i}, p_{k}\right)+q_{i}\left(p_{i}, p_{k}\right) \partial_{p_{i}} q_{i}\left(p_{i}, p_{k}\right) \\
\\
+\sigma q_{i}\left(p_{i}, p_{k}\right)\left(\partial_{p_{i}} q_{k}\left(p_{i}, p_{k}\right)+\partial_{p_{i}} q_{i}\left(p_{i}, p_{k}\right)\right)=0 .
\end{aligned}
$$

Consider now the merger between the two firms, and assume away any possible cost savings $(\lambda=0)$. The merged entity's problem is to maximize $\pi_{i, k}^{i n v}$ with respect to prices and investments, with $\pi_{i, k}^{i n v} \equiv \sum_{i \neq k}\left[p_{i}-c+x_{i}+\sigma x_{k}\right] q_{i}\left(p_{i}, p_{k}\right)-x_{i}^{2} / 2$.

Solving the FOC with respect to the investment $x_{i}$ (we omit the FOC with respect to $j$, since it is identical) gives $x_{i}=q_{i}\left(p_{i}, p_{k}\right)+\sigma q_{k}\left(p_{i}, p_{k}\right)$; thus, prices being equal, the merged entity invests more because it internalizes that an investment in good $i$ 's production will also benefit good $k$. After replacing $x_{i}$ and $x_{k}$ the merged entity's program becomes:

$$
\max _{p_{i}, p_{k}} \pi_{i, k}^{i n v}=\sum_{i \neq k}\left(p_{i}-c\right) q_{i}\left(p_{i}, p_{k}\right)+\frac{\left(q_{i}\left(p_{i}, p_{k}\right)+\sigma q_{k}\left(p_{i}, p_{k}\right)\right)^{2}}{2} .
$$

Taking the FOC with respect to $p_{i}$, and using symmetry, we obtain:

$$
\begin{aligned}
\partial_{p_{i}} \pi_{i, k}^{i n v}= & q_{i}\left(p_{i}, p_{k}\right)+\left(p_{i}-c\right) \partial_{p_{i}} q_{i}\left(p_{i}, p_{k}\right)+q_{i}\left(p_{i}, p_{k}\right) \partial_{p_{i}} q_{i}\left(p_{i}, p_{k}\right) \\
& +\sigma \partial_{p_{i}} q_{i}\left(p_{i}, p_{k}\right)\left(q_{i}\left(p_{i}, p_{k}\right)+q_{k}\left(p_{i}, p_{k}\right)\right) \\
& +\left(p_{k}-c+q_{i}\left(p_{i}, p_{k}\right)\right) \partial_{p_{i}} q_{k}\left(p_{i}, p_{k}\right)+\sigma \partial_{p_{i}} q_{i}\left(p_{i}, p_{k}\right)\left(q_{i}\left(p_{i}, p_{k}\right)+q_{k}\left(p_{i}, p_{k}\right)\right) \\
& +\sigma^{2}\left(q_{i}\left(p_{i}, p_{k}\right) \partial_{p_{i}} q_{i}\left(p_{i}, p_{k}\right)+q_{k}\left(p_{i}, p_{k}\right) \partial_{p_{i}} q_{k}\left(p_{i}, p_{k}\right)\right)=0 .
\end{aligned}
$$

We can now compare the ensuing equilibria by inspecting the FOCs at the benchmark and at the merger, respectively (30) and (31). The first four terms of (31) are identical to expression (30), hence at the benchmark equilibrium they must equal zero. If $\sigma=0$, that is, absent spillovers, the only difference between the two FOCs is represented by the term $\left(p_{k}-c+q_{i}\left(p_{i}, p_{k}\right)\right) \partial_{p_{i}} q_{k}\left(p_{i}, p_{k}\right)$, which is the usual upward pricing pressure effect of mergers. Therefore, absent spillovers the merger would lead to higher prices (and - after replacement in the investment FOC - into lower investments). When $\sigma>0$, however, there is an effect 
of opposite sign, that is, pushing prices downwards. Indeed, the last line in expression (31) is negative. Therefore, the higher the spillover $\sigma$ the more likely that the equilibrium price is lower under the merger; and the investment will be higher, due both to the internalization of the spillover and the lower price.

This means that there is a close parallel between the model with involuntary spillovers and the model with economies of scale in the investment function: in both cases, the merger will allow to internalize an externality.

\subsection{Sequential choices}

The game where firms simultaneously choose both cost-reducing investments and prices can be interpreted as one where investments cannot be observed by rivals when firms take pricing decisions. In this section, we look at sequential moves, i.e. the case where firms know all investments made at the time they set prices.

As in the previous subsection, we begin by looking at the benchmark (status quo) case with $n$ symmetric independent firms, and then at the merger between two out of these $n$ firms. Unfortunately though, in the sequential moves case we cannot rely on either the transformation from a bi-dimensional into a one-dimensional variable maximization problem or the aggregate game formulation, so we shall limit ourselves to compare the FOCs at the benchmark and at the merger, and resort to parametric models to gain some insight on the net effects of the merger.

\subsubsection{Benchmark with independent firms}

If firms act independently, in the second stage each firm $i$ solves the following problem:

$$
\max _{p_{i}} \tilde{\pi}_{i}\left(p_{i}, \bar{p}_{-i}, x_{i}\right)=\left(p_{i}-c\left(x_{i}\right)\right) q_{i}\left(p_{i}, \bar{p}_{-i}\right)-F\left(x_{i}\right), i=1, \ldots, n
$$

The FOCs are:

$$
\partial_{p_{i}} \tilde{\pi}_{i}(\cdot)=q_{i}\left(p_{i}, \bar{p}_{-i}\right)+\partial_{p_{i}} q_{i}\left(p_{i}, \bar{p}_{-i}\right)\left(p_{i}-c\left(x_{i}\right)\right)=0
$$

Assume the system of $n$ FOCs is uniquely solved by the vector of equilibrium prices, $\bar{p}^{b}(\bar{x})=$ $\left(p_{1}^{b}(\bar{x}), p_{2}^{b}(\bar{x}), \ldots, p_{n}^{b}(\bar{x})\right)$, which is function of the vector $\bar{x}=\left(x_{1}, x_{2}, \ldots, x_{n}\right)$ of the $n$ cost-reducing investments.

In the first stage, firms maximize $\tilde{\pi}_{i}\left(\bar{p}^{b}(\bar{x}), x_{i}\right)$ with respect to $x_{i}$, which, invoking the envelope theorem, yields the following system of FOCs:

$$
\partial_{x_{i}} \tilde{\pi}_{i}(\cdot)=-c^{\prime}\left(x_{i}\right) q_{i}\left(\bar{p}^{b}(\bar{x})\right)-F^{\prime}\left(x_{i}\right)+(n-1) \frac{d p_{j}^{b}}{d x_{i}} \partial_{p_{j}} q_{i}\left(\bar{p}^{b}(\bar{x})\right)\left(p_{i}^{b}(\bar{x})-c\left(x_{i}\right)\right)=0,
$$

for all $i=1, \ldots, n$ and $j \neq i$. The conditions in (33) define the equilibrium level of investment in the sequential choice game with independent firms. ${ }^{43}$ The difference between (33) and (2) is that, with sequential moves, each firm $i$ takes into account that raising its investment reduces the prices set by its rivals, and this will impact negatively own profits since it makes price

\footnotetext{
${ }^{43}$ For the stability and the unicity of the equilibrium at the investment stage in the benchmark and with the merger, we invoke the conditions derived in Kolstad and Mathiesen (1987). We will check that they are satisfied within the parametric models that we refer to below.
} 
competition more fierce. This effect is reflected by the last term in (33). As a consequence, the equilibrium investment values in $\bar{x}^{b}(\bar{p})$, as set by each firm $i$ solving conditions (33) in the benchmark model with sequential moves, will be lower than in the simultaneous moves case, ceteris paribus.

\subsubsection{Merger between firm $i$ and firm $k$}

In the second stage, the two merging firms $i$ and $k$ solve:

$$
\max _{p_{i}, p_{k}} \tilde{\pi}_{i, k}=\left(p_{i}-c\left(x_{i}\right)\right) q_{i}\left(p_{i}, \bar{p}_{-i}\right)+\left(p_{k}-c\left(x_{k}\right)\right) q_{k}\left(p_{k}, \bar{p}_{-k}\right)-F\left(x_{i}\right)-F\left(x_{k}\right)+\lambda G\left(x_{i}, x_{k}\right),
$$

with $i \neq k$. The FOC with respect to $p_{i}$ (we omit that for $p_{k}$ which is symmetric) is:

$$
\partial_{p_{i}} \tilde{\pi}_{i, k}=q_{i}\left(p_{i}, \bar{p}_{-i}\right)+\partial_{p_{i}} q_{i}\left(p_{i}, \bar{p}_{-i}\right)\left(p_{i}-c\left(x_{i}\right)\right)+\partial_{p_{i}} q_{k}\left(p_{k}, \bar{p}_{-k}\right)\left(p_{k}-c\left(x_{k}\right)\right)=0 .
$$

These FOCs are the same as in the simultaneous moves case: thus, since $\partial_{p_{i}} q_{k}\left(p_{k}, \bar{p}_{-k}\right) \geq 0$ and $p_{k}>c\left(x_{k}\right)$ at the equilibrium, and for given investments, the merger increases the price set by each insider with respect to the benchmark.

As for the outsiders, their FOCs will be the same as in the benchmark.

Let us call $\bar{p}^{m}(\bar{x})$ the vector of the prices which solves the system of the $n$ FOCs above, and note that it will be composed of the two insiders' prices, $p_{i}^{m}(\bar{x})=p_{k}^{m}(\bar{x})$ and $(n-2)$ symmetric outsiders' prices $p_{j}^{m}(\bar{x})$ with $j \neq i, k$.

In the first stage, insiders maximize joint profits $\tilde{\pi}_{i, k}=\tilde{\pi}_{i}\left(\bar{p}^{m}(\bar{x}), x_{i}\right)+\tilde{\pi}_{k}\left(\bar{p}^{m}(\bar{x}), x_{k}\right)$ with respect to $x_{i}$ and $x_{k}$. Using the envelope theorem, the associated FOCs are as follows:

$$
\begin{aligned}
& \partial_{x_{i}} \tilde{\pi}_{i, k}=-c^{\prime}\left(x_{i}\right) q_{i}\left(\bar{p}^{m}(\bar{x})\right)-F^{\prime}\left(x_{i}\right)+\lambda \partial_{x_{i}} G\left(x_{i}, x_{k}\right) \\
& \quad+(n-2) \frac{d p_{j}}{d x_{i}}\left[\partial_{p_{j}} q_{i}\left(\bar{p}^{m}(\bar{x})\right)\left(p_{i}^{m}(\bar{x})-c\left(x_{i}\right)\right)+\partial_{p_{j}} q_{k}\left(\bar{p}^{m}(\bar{x})\right)\left(p_{k}^{m}(\bar{x})-c\left(x_{k}\right)\right)\right]=0
\end{aligned}
$$

for all $j \neq i, k .^{44}$

As for the outsiders, their FOCs will have the same terms as those in the benchmark, except that different prices are anticipated as solution of the last stage of the game:

$$
\partial_{x_{j}} \tilde{\pi}_{j}(\cdot)=-c^{\prime}\left(x_{j}\right) q_{j}\left(\bar{p}^{m}(\bar{x})\right)-F^{\prime}\left(x_{j}\right)+\sum_{l \neq j} \frac{d p_{l}^{m}}{d x_{j}} \partial_{p_{l}} q_{j}\left(\bar{p}^{m}(\bar{x})\right)\left(p_{j}^{m}(\bar{x})-c\left(x_{j}\right)\right)=0 .
$$

Let us now compare the FOCs with respect to investments in the merger, (35) and (36), with those of the benchmark, (33). As for the insiders', there are three different effects at work. Two are of the same nature as in the simultaneous case: (i) since the insiders anticipate that they will sell lower quantities than at the benchmark $\left(q_{i}\left(\bar{p}^{m}(\bar{x})\right)<q_{i}\left(\bar{p}^{b}(\bar{x})\right)\right.$ because insiders' prices increase more than outsiders'), this will reduce the marginal revenue from investment, consisting of the term $-c^{\prime}\left(x_{i}\right) q_{i}\left(\bar{p}^{m}(\bar{x})\right)$. This will tend to lower investments by insiders. (ii) To the extent that efficiency gains exist $(\lambda>0)$, the term $\lambda \partial_{x_{i}} G\left(x_{i}, x_{k}\right)$ will decrease marginal costs from investing, and hence will tend to increase insiders' investments.

However, (iii) a new effect of the merger exists, and can be seen by comparing the last "strategic" term on the left-hand side (LHS) of expressions (33) and (35). In the benchmark

\footnotetext{
${ }^{44}$ The FOC of an outsider is isomorphic to the one of a firm in the benchmark (33), and therefore not reported.
} 
configuration of the sequential game, each firm takes into account that investing an additional dollar will lower its own costs and prices, but also (by strategic complementarity) the prices of all the $(n-1)$ rivals - and this will impact negatively on own profits. A merged entity, though, will take into account that an additional dollar invested in product $i$ will lower the prices of the $(n-2)$ outsiders, and that this will impact negatively on both the profits from product $i$ and from product $k$, and therefore tends to further reduce the incentive to invest by the merged firms with respect to the benchmark. ${ }^{45}$

As for the outsiders' FOCs, there will be a similar effect as in the simultaneous game: since outsiders anticipate they will sell more than in the benchmark at the last stage of the game, they will have a higher marginal revenue from investing, and this will raise their investments at the merger equilibrium.

Beyond these considerations on the different effects at work, it is difficult to establish general results on the net effect that a merger may have - even in the case where no efficiency gains exist - due to the impossibility of resorting to an aggregative game formulation, which is not available for sequential games. ${ }^{46}$ In order to get some insights into the effects of a merger in a sequential game, we therefore turn to some specific functional form oligopoly models.

\subsubsection{The merger in parametric models with sequential choices}

We have studied the sequential game for two different standard differentiated product models, the non-address model characterized by the Shubik-Levitan demand function, and the (address) Salop circle model, under the same assumptions made in the simultaneous model. To illustrate the results we report the solutions for particular parameter values in Table 2.

The results for the sequential model are of the same qualitative nature as for the simultaneous model. The merger always raises the insiders' prices, and it may increase or decrease the outsiders' prices; it always lowers insiders' investments and increases outsiders', but with the former effect dominating so that at equilibrium total investments are always lower than at the benchmark; profits of insiders and outsiders alike increase with the merger; consumers are always harmed by the merger, but total surplus may increase with the merger in particular circumstances. To be more precise, it never increases in the Shubik-Levitan model, but in the Salop model it rises for $t \in[0.6,0.746)$ - namely, for values where substitutability among the goods is very high - and decreases for $t \geq 0.746$ (we impose $t \geq 0.6$ to ensure profitability of the merger). Recall, though, that the Salop model is very special because aggregate demand is completely inelastic, and the higher prices caused by the merger do not entail any deadweight loss.

\footnotetext{
${ }^{45}$ The comparison between the two last terms in the FOCs (33) and (35), however, is somehow limited by two other elements: (a) there are $(n-1)$ terms to be summed up in (33), but only $(n-2)$ in (35); and (b) the marginal effect on own profits caused by a reduction in the rivals' prices may differ because the marginal profits are evaluated at two different price equilibria.

${ }^{46}$ Interestingly, in the sequential case even dealing with the merger to monopoly is not straightforward. Consider for simplicity the case $\lambda=0$. When $n=2$, the strategic term $\partial_{p_{j}} q_{i}\left(\bar{p}^{b}(\bar{x})\right)\left(p_{i}^{b}(\bar{x})-c\left(x_{i}\right)\right) d p_{j}^{b} / d x_{i}$ disappears from the investment FOCs of the merged entity: while in the benchmark a firm will tend to reduce its investment because it anticipates that this will make competition in the product market fiercer, the insiders' will internalize this effect, so this effect would tend to increase investment relative to the benchmark: a priori, we cannot establish whether this effect may or may not outweigh the effect (see (i) above) due to the lower sales expected in the monopoly equilibrium.
} 
Table 2: Equilibrium outcomes with sequential moves

\begin{tabular}{l|c|c|c}
\hline \hline & Shubik-Levitan & \multicolumn{2}{|c}{ Salop } \\
\hline & $a=2, \gamma=0.3$ & $t=0.9$ & $t=1.8$ \\
\hline \hline$p^{b}$ & 0.93 & 0.97 & 1.33 \\
$p_{I}^{m}$ & 1.08 & 1.17 & 1.78 \\
$p_{O}^{m}$ & 0.92 & 1.02 & 1.53 \\
$q^{b}$ & 0.67 & 0.33 & 0.33 \\
$q_{I}^{m}$ & 0.53 & 0.23 & 0.26 \\
$q_{I}^{m}$ & 0.76 & 0.54 & 0.47 \\
$x^{b}$ & 0.65 & 0.27 & 0.27 \\
$x_{I}^{m}$ & 0.51 & 0.15 & 0.18 \\
$x_{O}^{m}$ & 0.73 & 0.36 & 0.31 \\
$\pi^{b}$ & 0.18 & 0.04 & 0.16 \\
$\pi_{I}^{m}+\pi_{I}^{m}$ & 0.37 & 0.12 & 0.47 \\
$\pi_{O}^{m}$ & 0.23 & 0.14 & 0.35 \\
$C S^{m}-C S^{b}$ & -0.18 & -0.14 & -0.35 \\
$W^{m}-W^{b}$ & -0.11 & -0.002 & -0.02 \\
\hline \hline
\end{tabular}

\subsection{Network Sharing Agreements and Research Joint Ventures}

When assessing a merger proposal, the merger has to be compared with the likely counterfactuals. The status quo (what we call benchmark) is an obvious counterfactual, but in the case of efficiency gains from investment, another natural counterfactual candidate is a situation where some firms agree upon investment decisions, while continuing to behave independently in the product market. Examples of cooperative agreements at the investment stage include Research Joint Ventures (RJVs), where firms set joint R\&D programs but then independently market their innovation, and Network Sharing Agreements (NSAs), where Mobile Network Operators (MNOs) share infrastructure (such as sites, antennas, and other equipment) and/or spectrum, but compete in the retail markets where they sell mobile services independently.

In this section, we consider this type of agreements. We assume that the members of a NSA (or RJV), firms $i$ and $k$, choose investment levels $x_{i}$ and $x_{k}$ to maximize joint profits, but they choose prices to maximize individual profits. We consider the case of simultaneous investments and price decisions.

Since we assume that NSA members $i$ and $k$ maximize joint profits when setting investment, and behave non-cooperatively when setting the price, ${ }^{47}$ the FOCs of a NSA-member firm $i$ are

\footnotetext{
${ }^{47}$ While this appears natural in a sequential move game, it may appear less so in a simultaneous move game. However, NSAs are often structured in such a way that investment decisions are fully delegated to a separate joint venture whose managers are to behave independently from the managers of the parent companies. Independence between investment decisions and price decisions is also often a requirement of competition agencies to authorise the NSA. Note that if the NSA were to maximize joint profits with respect to both investments and prices, it would simply be identical to a merger.
} 
(we omit those for $k$, which are symmetric, and those for the outsiders, which are unchanged):

$$
\begin{aligned}
& \partial_{p_{i}} \tilde{\pi}_{i, k}=q_{i}\left(p_{i}, \bar{p}_{-i}\right)+\partial_{p_{i}} q_{i}\left(p_{i}, \bar{p}_{-i}\right)\left(p_{i}-c\left(x_{i}\right)\right)=0 \\
& \partial_{x_{i}} \tilde{\pi}_{i, k}=-\partial_{x_{i}} c\left(x_{i}\right) q_{i}\left(p_{i}, \bar{p}_{-i}\right)-\partial_{x_{i}} F\left(x_{i}\right)+\frac{\lambda}{2} \partial_{x_{i}} G\left(x_{i}, x_{k}\right)=0 .
\end{aligned}
$$

The FOC for the price is as in the benchmark (no merger), while the FOC for the investment of an insider firm $i$ is the same as in the merger. As we will show, this implies that, in the simultaneous moves case, the NSA will (weakly) dominate the benchmark in terms of consumer welfare, since it allows the members to the agreement to benefit from efficiency gains.

\subsubsection{Comparing the NSA with the benchmark}

We now provide a formal comparison between the NSA and the benchmark equilibrium outcomes.

Let us begin with the case with $n=2$ - we make use of the transformation of the model in one-action only. Since investments are taken cooperatively by $i$ and $k$, we can write the maximization problem of a NSA member as $\max _{p_{i}} \pi_{i}\left(p_{i}, p_{k} \mid \lambda\right)$, subject to $x_{i}=\chi\left(q_{i} \mid \lambda\right), q_{i}=$ $q_{i}\left(p_{i}, p_{k}\right)$, and

$$
\pi_{i}\left(p_{i}, p_{k} \mid \lambda\right)=\left(p_{i}-c\left(\chi\left(q_{i} \mid \lambda\right)\right)\right) q_{i}-F\left(\chi\left(q_{i} \mid \lambda\right)\right)+\frac{\lambda}{2} G\left(\chi\left(q_{i} \mid \lambda\right), \chi\left(q_{k} \mid \lambda\right)\right) .
$$

In (39), we assume that NSA firms, being symmetric, equally share the efficiencies generated by the deal. When comparing the equilibrium outcomes in the benchmark and in the NSA, we then find the following.

Proposition 7. For $n=2$, the NSA (weakly) lowers prices and (weakly) increases investments with respect to the benchmark for any value of $\lambda \geq 0$. This holds strictly for $\lambda>0$. For $n \geq 3$, the NSA (weakly) raises the aggregate with respect to the benchmark for any value of $\lambda \geq 0$.

The intuition behind this result comes from the fact that the NSA does not distort price choices while at the same time allowing its members to benefit from cost savings in the investment function.

For the case of $n \geq 3$ firms, we rely on the aggregative formulation and obtain an analogous result: the NSA raises the aggregate with respect to the benchmark. It then increases consumer surplus and investments under the sufficient conditions given in Section 2.3.

\subsubsection{Comparing the NSA with the merger}

What is more difficult to prove is that the NSA is superior to the merger from the point of view of consumers: one cannot exclude a priori that responses by outsiders may more than offset the effects on the insiders. ${ }^{48}$

We nevertheless can make use of the result in Propositions 2 (for $n=2$ ) and Lemma 11 (for $n \geq 3$ ) that it exists a threshold value of efficiency gains $\tilde{\lambda}$ such that, compared to the

\footnotetext{
${ }^{48}$ For instance, when comparing the merger and the NSA equilibria, the merger leads to higher prices by the insiders and (by strategic complementarity) by the outsiders, a decrease in the quantities sold by the former and an increase for the latter: in principle, it may be that the investments by the outsiders raise more than the decrease in investments by the insiders.
} 
benchmark, the merger lowers welfare for all $\lambda<\tilde{\lambda} \cdot{ }^{49}$ Since the NSA clearly dominates the benchmark for any value of $\lambda$, we then know that the NSA improves welfare with respect to the merger for all $\lambda<\tilde{\lambda}$. For $\lambda \geq \tilde{\lambda}$, both the merger and the NSA increase consumer welfare when compared to the benchmark. The following corollary recapitulates:

Proposition 8. The NSA raises consumer welfare with respect to the merger for all $\lambda<\tilde{\lambda}$. If $\lambda \geq \tilde{\lambda}$, both the merger and the NSA increase consumer welfare when compared to the benchmark.

\subsubsection{Parametric analysis of the NSA}

We now analyze the NSA within two specific functional forms models (the Shubik-Levitan and Salop model we have seen above), and the comparison among the merger, benchmark and NSA equilibrium outcomes suggest that the NSA is (weakly) better for consumers than both the merger and the benchmark.

Figure 4, obtained for the Shubik-Levitan model, illustrates that for whatever level of efficiency gains a NSA performs (weakly) better than both the merger and the benchmark: total investments and consumer surplus are always strictly higher under the NSA (the same would hold for total surplus) for any $\lambda>0$, and they coincide with the benchmark equilibria for $\lambda=0$. In line with the analysis of the merger in Section 2.2, there exists a level $\lambda$ of efficiency gains at which the merger leads to higher investments than the benchmark (but never than the NSA) but that a still higher level is necessary to offset the increase in prices: $C S^{m}=C S^{b}$ at a higher level of $\lambda .^{50}$

Figure 4: Merger and NSA with efficiency gains and simultaneous moves

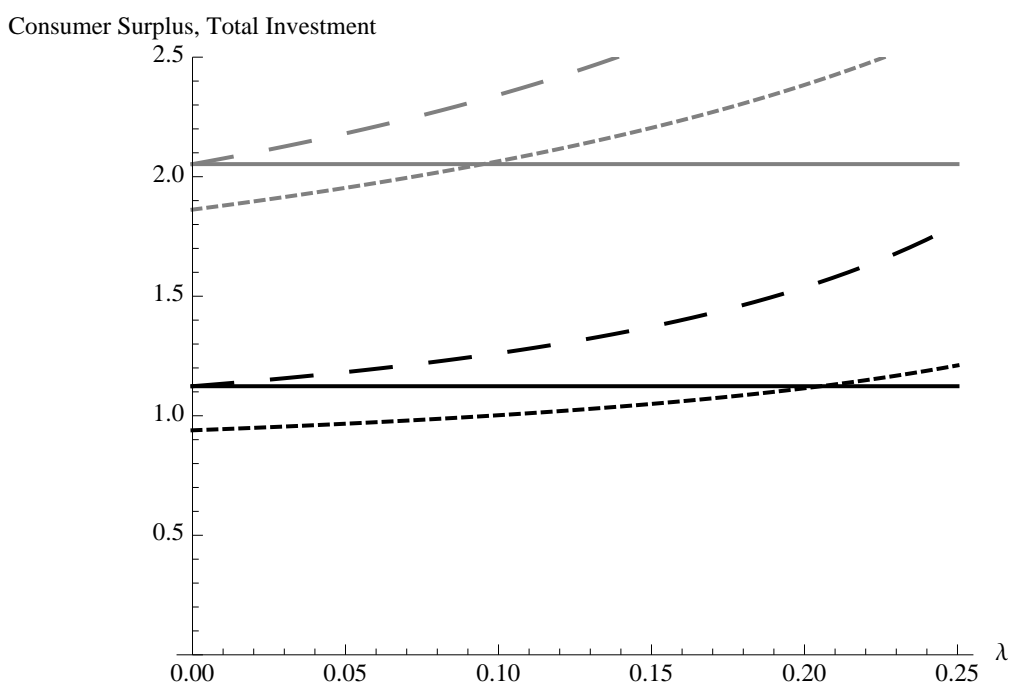

Note: the black lines refer to consumer surplus and the grey lines to total investments. Moreover, the solid lines correspond to the benchmark, the dotted lines to the merger and the dashed lines to the NSA/RJV. The parametric values we use are $n=3, \alpha=2$, $c=1$ and $\gamma=0.3$. The range for $\lambda$ is chosen so that all parametric restrictions are satisfied.

\footnotetext{
${ }^{49}$ More specifically, when $n \geq 3, \lambda \geq \tilde{\lambda}$ directly implies a larger surplus only when the IIA property holds.

${ }^{50}$ We obtain similar results with the Salop model (see the previous version of the paper).
} 


\section{Summary, and some policy implications}

It has been suggested that mergers, by increasing profitability, will also result in higher investments and surplus. To deal with this claim, we have studied a model with simultaneous cost-reducing investments and price choices and found that - absent efficiency gains in investments - the merger is anti-competitive: it lowers both investment and consumer surplus. We have also showed that the same results arise in several classes of models where firms invest to enhance the quality of their products, rather than to reduce their costs.

In the light of these results, we find no support for the view that a merger - by relaxing competition - might increase incentives to invest. Rather, we have showed that, absent cost savings from the merger, both in the general model and in all the (standard) parametric models analyzed, the merging firms will always reduce their investments. Furthermore, we have established sufficient conditions for the merger to reduce aggregate investments.

Therefore, absent efficiency gains, the well-known detrimental effects of the merger are confirmed in an environment where firms set not only prices but also investments. This does not mean, of course, that a merger will always be anti-competitive in practice. Indeed, it is possible that by combining their assets two firms will be able to reduce the costs of their investment: if these efficiency gains were large enough, they might increase investments so much as to outweigh the usual detrimental effect of the merger on prices.

However, a remark is in order. We have showed that to the extent that the same efficiency gains can be achieved by a Network-Sharing Agreement (or, if we were talking about innovations rather than investments, by a $R \& D$ cooperative agreement), such an agreement is likely to be superior to the merger from the welfare point of view. This implies that the merging parties should prove not only that the merger will lead to dynamic efficiencies, but also that such efficiencies are merger-specific (that is, they cannot be reached by a less anti-competitive agreement).

One could think of environments where mergers may lead to higher investments even absent efficiency gains, due to the fact that higher profits may relax financial constraints. It would be straightforward to write a model where insufficient profits would limit access to external funding, and consolidation would bring higher earnings that the merged entity could use to finance valuable projects that otherwise would not carry out. However, this positive effect would in general be in conflict with the mechanisms highlighted in this paper, and an analysis of the ensuing trade-off between ability and incentive to invest would be interesting and not obvious. Note also that for this beneficial effect to hold it must be that - absent the merger - the firms are unable to carry out valuable investments because financially constrained, something that they would need to substantiate with evidence. 


\section{Appendix}

Proof of Proposition 1. Omitting functional notation for $q_{i}$ and $q_{k}$, the FOC with respect to $p_{i}$ is given by: ${ }^{51}$

$$
\begin{aligned}
& \partial_{p_{i}} \pi_{i, k}=\left(p_{i}-c\left(\chi\left(q_{i}\right)\right)\right) \partial_{p_{i}} q_{i}+q_{i}-\frac{d c\left(\chi\left(q_{i}\right)\right)}{d p_{i}} q_{i}-\frac{d F\left(\chi\left(q_{i}\right)\right)}{d p_{i}} \\
& \quad+\left(p_{k}-c\left(\chi\left(q_{k}\right)\right)\right) \partial_{p_{i}} q_{k}-\frac{d c\left(\chi\left(q_{k}\right)\right)}{d p_{i}} q_{k}-\frac{d F\left(\chi\left(q_{k}\right)\right)}{d p_{i}}=0 \\
&=\left(p_{i}-c\left(\chi\left(q_{i}\right)\right)\right) \partial_{p_{i}} q_{i}+q_{i}+\left(p_{k}-c\left(\chi\left(q_{k}\right)\right)\right) \partial_{p_{i}} q_{k}=0 .
\end{aligned}
$$

The second equality follows from (11), (12) and $q=-F^{\prime} / c^{\prime}$, with $q=\left\{q_{i}, q_{k}\right\}$. After imposing symmetry, $p_{i}=p_{k}=p^{m}$, we find that the equilibrium price set by the new entity is implicitly defined by

$$
p^{m}=c\left(\chi\left(q_{i}^{m}\right)\right)-\frac{q_{i}^{m}}{\partial_{p_{i}} q_{i}^{m}+\partial_{p_{i}} q_{k}^{m}}>c\left(\chi\left(q_{i}^{m}\right)\right),
$$

where $q_{i}^{m} \equiv q_{i}\left(p^{m}, p^{m}\right)$. Existence and unicity of $p^{m}$ are guaranteed by $(A 0)$. That $p^{m}>c(\cdot)$ is a consequence of $\partial_{p_{i}} q_{i}^{m}+\partial_{p_{i}} q_{k}^{m}>0$, which holds by symmetry and the assumption that own price effects are larger than cross price effects.

To show that the price level rises with the merger, $p^{m}>p^{b}$, we evaluate (A-1) at $p_{i}=p^{b}$. Let $q_{i}^{b} \equiv q_{i}\left(p^{b}, p^{b}\right)$, by (8), we have

$$
\left(p^{b}-c\left(\chi\left(q_{i}^{b}\right)\right)\right) \partial_{p_{i}} q_{i}^{b}+q_{i}^{b}=0,
$$

so the first two terms in (A-1) equal zero, but the remaining term $\left(p^{b}-c\left(\chi\left(q_{k}^{b}\right)\right)\right) \partial_{p_{i}} q_{k}^{b}>0$ since $\partial_{p_{i}} q_{k}^{b}>0$. As a result, $\partial_{p_{i}} \pi_{i, k}>0$ at $p_{i}=p_{k}=p^{b}$ and the prices after the merger must increase to a price $p^{m}$ above $p^{b}$ in order to maximize profits. But since prices increase, the quantity of each brand sold by the merged entity must fall, $q_{i}^{m}<q_{i}^{b}$. All this yields also a fall in equilibrium investments in (11) and (12), because $\chi^{\prime} \geq 0$.

Q.E.D.

Proof of Lemma 3. First, we show that a similar transformation to the one operated in Lemma 1 applies to the merger problem in the presence of efficiency gains.

The investment FOC of firm $i$ can be rewritten as:

$$
\begin{aligned}
\partial_{x_{i}} \tilde{\pi}_{i, k} & =-c^{\prime}\left(x_{i}\right) q_{i}\left(p_{i}, p_{k}\right)=F^{\prime}\left(x_{i}\right)-\lambda \partial_{x_{i}} G\left(x_{i}, x_{k}\right) \\
& \Longleftrightarrow \quad-\frac{F^{\prime}\left(x_{i}\right)-\lambda \partial_{x_{i}} G\left(x_{i}, x_{k}\right)}{c^{\prime}\left(x_{i}\right)}=q_{i}\left(p_{i}, p_{k}\right) .
\end{aligned}
$$

At the symmetric equilibrium, $x_{i}=x_{k}=x$. Then,

$$
-\frac{F^{\prime}(x)-\lambda \partial_{x_{i}} G(x, x)}{c^{\prime}(x)}=q_{i}\left(p_{i}, p_{k}\right) .
$$

Let $-\left(F^{\prime}(x)-\lambda \partial_{x_{i}} G(x, x)\right) / c^{\prime}(x) \equiv \phi(x \mid \lambda)$. Since $F^{\prime}(\cdot)-\lambda \partial_{x_{i}} G(\cdot, \cdot) \geq 0, c^{\prime}(\cdot)<0, F^{\prime \prime}(\cdot)-$ $\lambda \partial_{x_{i} x_{i}}^{2} G(\cdot, \cdot) \geq 0$ and $c^{\prime \prime}(\cdot) \geq 0$, it follows that $\partial_{x} \phi(\cdot \mid \lambda) \geq 0 .{ }^{52}$ Hence, $\phi(\cdot \mid \lambda)$ is invertible and

$$
x=\phi^{-1}\left(q_{i}\left(p_{i}, p_{k}\right) \mid \lambda\right) \equiv \chi\left(q_{i}\left(p_{i}, p_{k}\right) \mid \lambda\right),
$$

\footnotetext{
${ }^{51}$ The FOC with respect to $p_{k}$ is analogous, thus omitted.

${ }^{52}$ The calculations are analogous to those in the proof of Lemma 1.
} 
with $\partial_{q} \chi(\cdot \mid \lambda) \geq 0$. Moreover, since $\partial_{\lambda} \phi(\cdot \mid \lambda)=\partial_{x_{i}} G(x, x) / c^{\prime}(x)<0$, then an increase in $\lambda$ raises $x_{i}$, i.e., $\partial_{\lambda} \chi(\cdot \mid \lambda)>0$.

Therefore, we can rewrite the merging firms' maximization problem as function of $p_{i}$ and $p_{k}$ only, in the presence of efficiency gains:

$$
\begin{aligned}
\max _{p_{i}, p_{k}} \pi_{i, k}= & \left(p_{i}-c\left(\chi\left(q_{i}\left(p_{i}, p_{k}\right) \mid \lambda\right)\right)\right) q_{i}\left(p_{i}, p_{k}\right)+\left(p_{k}-c\left(\chi\left(q_{k}\left(p_{i}, p_{k}\right) \mid \lambda\right)\right)\right) q_{i}\left(p_{i}, p_{k}\right) \\
& -F\left(\chi\left(q_{i}\left(p_{i}, p_{k}\right) \mid \lambda\right)\right)-F\left(\chi\left(q_{k}\left(p_{k}, p_{i}\right) \mid \lambda\right)\right)+\lambda G\left(\chi\left(q_{i}\left(p_{i}, p_{k}\right) \mid \lambda\right), \chi\left(q_{k}\left(p_{k}, p_{i}\right) \mid \lambda\right)\right) .
\end{aligned}
$$

Omitting functional notation for $q_{i}$ and $q_{k}$, the FOC with respect to $p_{i}$ is

$$
\begin{aligned}
\partial_{p_{i}} \pi_{i, k}= & \left(p_{i}-c\left(\chi\left(q_{i} \mid \lambda\right)\right)\right) \partial_{p_{i}} q_{i}+q_{i}+\left(p_{k}-c\left(\chi\left(q_{k} \mid \lambda\right)\right)\right) \partial_{p_{i}} q_{k} \\
& -\frac{d c\left(\chi\left(q_{i} \mid \lambda\right)\right)}{d p_{i}} q_{i}-\frac{d F\left(\chi\left(q_{i} \mid \lambda\right)\right)}{d p_{i}} \\
& -\frac{d c\left(\chi\left(q_{k} \mid \lambda\right)\right)}{d p_{i}} q_{k}-\frac{d F\left(\chi\left(q_{k} \mid \lambda\right)\right)}{d p_{i}} \\
& +\lambda \frac{d G\left(\chi\left(q_{i} \mid \lambda\right), \chi\left(q_{k} \mid \lambda\right)\right)}{d p_{i}}=0 .
\end{aligned}
$$

The analysis above implies that

$$
\begin{aligned}
& \frac{d c\left(\chi\left(q_{i} \mid \lambda\right)\right)}{d p_{i}}=c^{\prime}\left(\chi\left(q_{i} \mid \lambda\right)\right) \partial_{q_{i}} \chi\left(q_{i} \mid \lambda\right) \partial_{p_{i}} q_{i}, \frac{d c\left(\chi\left(q_{k} \mid \lambda\right)\right)}{d p_{i}}=c^{\prime}\left(\chi\left(q_{k} \mid \lambda\right)\right) \partial_{q_{k}} \chi\left(q_{k} \mid \lambda\right) \partial_{p_{i}} q_{k} \\
& \frac{d F\left(\chi\left(q_{i} \mid \lambda\right)\right)}{d p_{i}}=F^{\prime}\left(\chi\left(q_{i} \mid \lambda\right)\right) \partial_{q_{i}} \chi\left(q_{i} \mid \lambda\right) \partial_{p_{i}} q_{i}, \frac{d F\left(\chi\left(q_{k} \mid \lambda\right)\right)}{d p_{i}}=F^{\prime}\left(\chi\left(q_{k} \mid \lambda\right)\right) \partial_{q_{k}} \chi\left(q_{k} \mid \lambda\right) \partial_{p_{i}} q_{k}
\end{aligned}
$$

and

$$
\begin{aligned}
\frac{d G\left(\chi\left(q_{i} \mid \lambda\right), \chi\left(q_{k} \mid \lambda\right)\right)}{d p_{i}}= & \partial_{\chi} G\left(\chi\left(q_{i} \mid \lambda\right), \chi\left(q_{k} \mid \lambda\right)\right) \partial_{q_{i}} \chi\left(q_{i} \mid \lambda\right) \partial_{p_{i}} q_{i} \\
& +\partial_{\chi} G\left(\chi\left(q_{i} \mid \lambda\right), \chi\left(q_{k} \mid \lambda\right)\right) \partial_{q_{k}} \chi\left(q_{k} \mid \lambda\right) \partial_{p_{i}} q_{k}
\end{aligned}
$$

Then, by the envelope theorem,

$$
\frac{d c\left(\chi\left(q_{i} \mid \lambda\right)\right)}{d p_{i}} q_{i}+\frac{d F\left(\chi\left(q_{i} \mid \lambda\right)\right)}{d p_{i}}+\frac{d c\left(\chi\left(q_{k} \mid \lambda\right)\right)}{d p_{i}} q_{k}+\frac{d F\left(\chi\left(q_{k} \mid \lambda\right)\right)}{d p_{i}}+\lambda \frac{d G\left(\chi\left(q_{i} \mid \lambda\right), \chi\left(q_{k} \mid \lambda\right)\right)}{d p_{i}}=0 .
$$

As a consequence, the FOC in (A-5) reduces to

$$
\left(p_{i}-c\left(\chi\left(q_{i} \mid \lambda\right)\right)\right) \partial_{p_{i}} q_{i}+q_{i}+\left(p_{k}-c\left(\chi\left(q_{k} \mid \lambda\right)\right)\right) \partial_{p_{i}} q_{k}=0 .
$$

Under our assumptions, this FOC is sufficient for optimality; thus, in the unique symmetric equilibrium the merging firm sets

$$
p^{m}(\lambda)=c\left(\chi\left(q_{i}^{m} \mid \lambda\right)\right)-\frac{q_{i}^{m}}{\partial_{p_{i}} q_{i}^{m}+\partial_{p_{i}} q_{k}^{m}}, x^{m}(\lambda)=\chi\left(q_{i}^{m} \mid \lambda\right) .
$$

Next, suppose there is a higher level of efficiency gains, $\lambda^{\prime}>\lambda$. Since $\partial_{\lambda} c\left(\chi\left(q_{i}^{m} \mid \lambda\right)\right)=c^{\prime} \partial_{\lambda} \chi \leq 0$ and $\partial_{\lambda} \chi \geq 0$, it follows by the implicit function theorem that $p^{m}\left(\lambda^{\prime}\right)<p^{m}(\lambda)$ and $x^{m}\left(\lambda^{\prime}\right)>$ $x^{m}(\lambda)$.

Q.E.D. 
Proof of Lemma 4. If $p^{m}\left(\lambda^{b}\right)=p^{m}$ and $x^{m}\left(\lambda^{b}\right)=x^{b}$ denote the price and investment levels which solve the merged entity's problem when $\lambda=\lambda^{b}$, the merging firm FOC with respect to investments in (A-3) can be written as:

$$
\partial_{x_{i}} \pi_{i, k}=-\partial_{x_{i}} c\left(x^{b}\right) q_{i}\left(p^{m}, p^{m}\right)-\partial_{x_{i}} F\left(x^{b}\right)+\lambda \partial_{x_{i}} G\left(x^{b}, x^{b}\right)=0 .
$$

We also know that $\left(p_{b}, x_{b}\right)$ solve the FOC in the benchmark with $n=2(3)$. Hence, it must be true that:

$$
\partial_{x_{i}} \pi_{i}=-\partial_{x_{i}} c\left(x^{b}\right) q_{i}\left(p^{b}, p^{b}\right)-\partial_{x_{i}} F\left(x^{b}\right)=0 .
$$

The last two equations imply:

$$
\frac{\partial_{x_{i}} F\left(x^{b}\right)-\lambda \partial_{x_{i}} G\left(x^{b}, x^{b}\right)}{q_{i}\left(p^{m}, p^{m}\right)}=\frac{\partial_{x_{i}} F\left(x^{b}\right)}{q_{i}\left(p^{b}, p^{b}\right)} .
$$

Since $\partial_{x_{i}} F\left(x^{b}\right)-\lambda \partial_{x_{i}} G\left(x^{b}, x^{b}\right)<\partial_{x_{i}} F\left(x^{b}\right)$, for the above equality to hold it must be $q_{i}\left(p^{m}, p^{m}\right)<q_{i}\left(p^{b}, p^{b}\right)$. In turn, this is consistent only with $p^{m}>p^{b}$.

Q.E.D.

Proof of Lemma 5. Writing (17) as

$$
\frac{d \pi_{i}\left(A_{-i}+r_{i}\left(A_{-i}\right), r_{i}\left(A_{-i}\right)\right)}{d a_{i}}=0
$$

and taking its total derivative, yields

$$
\frac{d r_{i}\left(A_{-i}\right)}{d A_{-i}} \equiv r_{i}^{\prime}\left(A_{-i}\right)=-\frac{\partial_{a_{i} A_{-i}} \pi_{i}\left(A_{-i}+a_{i}, a_{i}\right)}{\partial_{a_{i} a_{i}} \pi_{i}\left(A_{-i}+a_{i}, a_{i}\right)}
$$

The denominator of this expression is negative by Assumption (A2) while Assumption (A3) implies that the ratio is strictly larger than -1 . The monotonicity of $A_{-i}+r_{i}\left(A_{-i}\right)$ immediately follows.

Q.E.D.

Proof of Lemma 6 . The total derivative of $\tilde{r}_{i}$ results from the observation that, since $\tilde{r}_{i}(A) \equiv$ $r_{i}\left(f_{i}(A)\right)$,

$$
\frac{d \tilde{r}_{i}(A)}{d A}=\frac{d r_{i}\left(A_{-i}\right)}{d A_{-i}} \frac{d f_{i}(A)}{d A}=r^{\prime}\left(A_{-i}\right) \frac{d f_{i}(A)}{d A}
$$

Moreover, since $A_{-i}=f_{i}(A)$ and $A_{-i}+r_{i}\left(A_{-i}\right)=A$, applying the implicit function theorem to $A_{-i}=f_{i}\left(A_{-i}+r_{i}\left(A_{-i}\right)\right)$ yields $d f_{i}(A) / d A=1 /\left(1+r_{i}^{\prime}\right)$. Hence,

$$
\frac{d \tilde{r}_{i}(A)}{d A}=\tilde{r}_{i}^{\prime}=\frac{r_{i}^{\prime}}{1+r_{i}^{\prime}}
$$

with $\tilde{r}_{i} \in(0,1)$ for all $r_{i}^{\prime}>0$ (as it holds true with strategic complementarity). Instead, with strategic substitutability, $r_{i}^{\prime} \in(-1,0)$ implies that $\tilde{r}_{i}^{\prime}<0$ for all the values of $A$ in which $r_{i}$ takes positive values (i.e., for all $A<\bar{A}_{-i}$ ).

Q.E.D. 
Proof of Lemma \%. By the definition of $\bar{A}_{-i}$, we have that $\tilde{r}_{i}(A)=0$ for all $A \geq \bar{A}_{-i}$. Hence, $\bar{\pi}_{i}(A)=0$ in this interval of values of $A$. For $A<\bar{A}_{-i}$,

$$
\frac{d \bar{\pi}_{i}(A)}{d A}=\frac{d \bar{\pi}_{i}\left(A, \tilde{r}_{i}(A)\right)}{d A}=\partial_{A} \pi_{i}\left(A, \tilde{r}_{i}(A)\right)+\partial_{a_{i}} \pi_{i}\left(A, \tilde{r}_{i}(A)\right) \frac{d \tilde{r}_{i}(A)}{d A} .
$$

From (17),

$$
\partial_{A} \pi_{i}\left(A, a_{i}\right)=-\partial_{a_{i}} \pi_{i}\left(A, a_{i}\right)
$$

implies that

$$
\partial_{A} \pi_{i}\left(A, \tilde{r}_{i}(A)\right)+\partial_{a_{i}} \pi_{i}\left(A, \tilde{r}_{i}(A)\right) \frac{d \tilde{r}_{i}(A)}{d A}=\partial_{A} \pi_{i}\left(A, \tilde{r}_{i}(A)\right)\left(1-\frac{d \tilde{r}_{i}(A)}{d A}\right) .
$$

Finally, (A1) together with Lemma 6 imply that (A-8) is negative, as $(A 1)$ implies that $\pi_{i}$ falls with $A$ for given $a_{i}$.

Q.E.D.

Proof of Lemma 8. For the existence of the fixed point, we check that the intermediate value theorem assumptions are satisfied. Denote by $\mathcal{A}$ the interval of values of $A$ :

1. The continuity of each $\tilde{r}_{i}, i=1, \ldots, n$, implies that also their sum is continuous.

2. Since individual strategies spaces are compact, also $\mathcal{A}$ must be compact.

3. $\sum_{i=1}^{n} \tilde{r}_{i}(A)$ takes values in $\mathcal{A}$.

Thus, it always exists a fixed point of the problem in (18).

For the uniqueness, a sufficient condition requires that $\sum_{i=1}^{n} \tilde{r}_{i}^{\prime}(A)<1$, as in (19). Q.E.D.

Proof of Lemma 9. By $(A 1), \pi_{k}\left(A, a_{k}\right)$ falls in $A$ and the third term in (21) is negative. It follows that $\tilde{r}_{i}^{m}(A)<\tilde{r}_{i}(A)$ for any value of $a_{k}$. Similarly, $\tilde{r}_{k}^{m}(A)<\tilde{r}_{k}(A)$ for all $a_{i} .{ }^{53}$ Thus, $\tilde{R}^{m}(A)<\tilde{r}_{i}(A)+\tilde{r}_{k}(A)$.

Q.E.D.

Proof of Proposition 5. First, due to firms' symmetry, we can define by $q^{b}$ the equilibrium quantity set by the firms in the benchmark, and by $q_{I}^{m}$ and $q_{O}^{m}$ the equilibrium quantities set by the insiders $(I)$ and outsiders $(O)$ with the merger, respectively. Given the results in Lemma 9 , the goal is to show the conditions under which $n \chi\left(q^{b}\right) \geq 2 \chi\left(q_{I}^{m}\right)+(n-2) \chi\left(q_{O}^{m}\right)$.

If the industry quantity is proportional to the aggregate $A$, then $n q^{b} \geq 2 q_{I}^{m}+(n-2) q_{O}^{m}$. While, by Lemma 9 , it is clear that $q_{I}^{m}<q^{b},{ }^{54}$ two cases must be considered with respect to the change in the quantity of the outsiders:

1. If $q_{O}^{m}<q_{b}$, then $\chi^{\prime} \geq 0$ implies that total and each firm's investment fall with the merger.

2. If $q^{b} \leq q_{O}^{m}$, then insiders' investment falls while outsiders' increases. In this case, a sufficient condition for total investments to decrease is that $\chi^{\prime \prime}(\cdot) \leq 0$. To prove this statement, we first denote $\bar{q} \equiv 2 q_{I}^{m} / n+(n-2) q_{O}^{m} / n$. Then, Jensen's inequality implies that

$$
\chi(\bar{q}) \geq \frac{n-2}{n} \chi\left(q_{I}^{m}\right)+\frac{2}{n} \chi\left(q_{O}^{m}\right) .
$$

\footnotetext{
${ }^{53}$ Due to products' symmetry, both insiders must be active after the merger takes place.

${ }^{54}$ The fall in $a_{i}$ and $a_{k}$ means that the price of the merging parties rises with the merger.
} 
If $q_{b}=\bar{q}$ and $\chi^{\prime \prime}<0$, the result immediately follows. It follows a fortiori if $q_{b}>\bar{q}$, as, in this case, $\chi^{\prime}(\cdot) \geq 0$ implies that $\chi\left(q_{b}\right)>\chi(\bar{q})$.

Finally, since Jensen's inequality holds only for concave functions, we need to prove that $\chi^{\prime \prime}(\cdot) \leq 0$ under our assumptions. By the properties of inverse functions, $\chi^{\prime \prime} \leq 0$ if and only if $\phi^{\prime \prime} \geq 0$, or

$$
\phi^{\prime \prime}\left(x_{i}\right)=\frac{\partial^{2}}{\partial x_{i}^{2}}\left(-\frac{F^{\prime}\left(x_{i}\right)}{c^{\prime}\left(x_{i}\right)}\right) \geq 0 .
$$

Taking the derivative in (A-9), and omitting functional notation, we find that

$$
\operatorname{sign}\left\{\phi^{\prime \prime}\right\}=\operatorname{sign}\left\{-\left\{\left(F^{\prime \prime \prime} c^{\prime}-c^{\prime \prime \prime} F^{\prime}\right)\left(c^{\prime}\right)^{2}-2 c^{\prime} c^{\prime \prime}\left(F^{\prime \prime} c^{\prime}-c^{\prime \prime} F^{\prime}\right)\right\}\right\} .
$$

Thus, $\phi^{\prime \prime}(\cdot) \geq 0$ under our restrictions on the functional forms of $c(\cdot)$ and $F(\cdot)$ (specifically, these assumptions require that $c^{\prime}<0, c^{\prime \prime} \geq 0, c^{\prime \prime \prime} \geq 0, F^{\prime} \geq 0, F^{\prime \prime} \geq 0$ and $\left.F^{\prime \prime \prime} \geq 0\right)$.

Q.E.D.

Proof of Lemma 10. The proof works in two steps. (1) We show that $d r_{i}(A \mid \lambda) / d \lambda>0$ if and only if $d^{2} \pi_{i}\left(A, a_{i} \mid \lambda\right) /\left(d a_{i} d \lambda\right)>0$. (2) We show that, under our assumptions, $d r_{i}(A \mid \lambda) / d \lambda>0$.

1. As observed in Lemma $6, \tilde{r}_{i}(A \mid \lambda)=r_{i}(f(A \mid \lambda) \mid \lambda)$, with $A_{-i}=f_{i}(A)$ and $A_{-i}+r_{i}\left(A_{-i} \mid \lambda\right)=$ A. Consequently,

$$
\frac{d \tilde{r}_{i}(A \mid \lambda)}{d \lambda}=\frac{d r_{i}\left(A_{-i} \mid \lambda\right)}{d A_{-i}} \frac{d f(A \mid \lambda)}{d \lambda}+\frac{d r_{i}\left(A_{-i} \mid \lambda\right)}{d \lambda}
$$

By the implicit function theorem, $d f(A \mid \lambda) / d \lambda=-\partial_{\lambda} r_{i} /\left(1+\partial_{A_{-i}} r_{i}\right)$; thus,

$$
\frac{d \tilde{r}_{i}(A \mid \lambda)}{d \lambda}=\frac{\partial_{\lambda} r_{i}}{1+\partial_{A_{-i}} r_{i}} .
$$

The denominator of (A-10) is positive by Lemma 5 , then the expression is positive if and only if $d^{2} \pi_{i}\left(A, a_{i} \mid \lambda\right) /\left(d a_{i} d \lambda\right)>0, \operatorname{as} \operatorname{sign}\left\{\partial_{\lambda} r_{i}\right\}=\operatorname{sign}\left\{d^{2}\left(\pi_{i}\left(A, a_{i} \mid \lambda\right)+\pi_{k}\left(A, a_{k} \mid \lambda\right)\right) /\left(d a_{i} d \lambda\right)\right\}$.

2. We now prove that, in our aggregative formulation of the game, it holds that $d^{2}\left(\pi_{i}\left(A, a_{i} \mid \lambda\right)+\right.$ $\left.\pi_{k}\left(A, a_{k} \mid \lambda\right)\right) /\left(d a_{i} d \lambda\right)>0$. First take the derivative of $\pi_{i}\left(A, a_{i} \mid \lambda\right)+\pi_{k}\left(A, a_{k} \mid \lambda\right)$ with respect to $a_{i}$. Using the envelope theorem (note that $q_{i}=q_{i}\left(A, a_{i}\right)$, but in what follows we omit the functional notation), this expression can be written as

$$
\left(\psi^{-1}\right)^{\prime} q_{i}+\left(\psi^{-1}-c\left(\chi\left(q_{i} \mid \lambda\right)\right)\right) \frac{d q_{i}}{d a_{i}}+\left(\psi^{-1}-c\left(\chi\left(q_{k} \mid \lambda\right)\right)\right) \partial_{a_{i}} q_{k}
$$

In turn, the derivative of the last expression with respect to $\lambda$ yields

$$
-c^{\prime}\left(\chi\left(q_{i} \mid \lambda\right)\right) \partial_{\lambda} \chi\left(q_{i} \mid \lambda\right) \frac{d q_{i}}{d a_{i}}-c^{\prime}\left(\chi\left(q_{k} \mid \lambda\right)\right) \partial_{\lambda} \chi\left(q_{k} \mid \lambda\right) \partial_{a_{i}} q_{k}
$$

Using symmetry, $q_{i}=q_{k}$, and the assumption that own action effects are larger than cross action effects, $d q_{i} / d a_{i}+\partial_{a_{i}} q_{k}>0$, we obtain that

$$
-c^{\prime}\left(\chi\left(q_{i} \mid \lambda\right)\right) \partial_{\lambda} \chi\left(q_{i} \mid \lambda\right)\left(\frac{d q_{i}}{d a_{i}}+\partial_{a_{i}} q_{k}\right)>0 .
$$


Q.E.D.

Proof of Lemma 11. First note that $A^{b}$ is independent of $\lambda$. Then, by Lemma 10, the FOC with respect to $a_{i}$ is strictly increasing in $\lambda$. Finally, invoking the intermediate value theorem as in the proof of Lemma 8 yields the unicity of $\tilde{\lambda}$.

Q.E.D.

Proof of Proposition \%. The proof develops in two parts, the first with $n=2$ and the second with $n \geq 3$.

Let $n=2$. After dropping the functional notation for $q_{i}$, the FOC of (39) with respect to $p_{i}$ is

$$
\begin{aligned}
&\left(p_{i}-c\left(\chi\left(q_{i} \mid \lambda\right)\right)\right) \partial_{p_{i}} q_{i}+q_{i}+\frac{\lambda}{2} \frac{d G\left(\chi\left(q_{i} \mid \lambda\right), \chi\left(q_{k} \mid \lambda\right)\right)}{d p_{i}} \\
&-\left(c^{\prime}\left(\chi\left(q_{i} \mid \lambda\right)\right) q_{i}+F^{\prime}\left(\chi\left(q_{i} \mid \lambda\right)\right)\right) \chi^{\prime}\left(q_{i} \mid \lambda\right) \partial_{p_{i}} q_{i}=0,
\end{aligned}
$$

where

$$
\begin{aligned}
\frac{d G\left(\chi\left(q_{i} \mid \lambda\right), \chi\left(q_{k} \mid \lambda\right)\right)}{d p_{i}}= & \partial_{\chi} G\left(\chi\left(q_{i} \mid \lambda\right), \chi\left(q_{k} \mid \lambda\right)\right) \partial_{q_{i}} \chi\left(q_{i} \mid \lambda\right) \partial_{p_{i}} q_{i} \\
& +\partial_{\chi} G\left(\chi\left(q_{i} \mid \lambda\right), \chi\left(q_{k} \mid \lambda\right)\right) \partial_{q_{k}} \chi\left(q_{k} \mid \lambda\right) \partial_{p_{i}} q_{k} .
\end{aligned}
$$

To compare the value of $p^{b}$ with the price set by a firm in the NSA, we evaluate the LHS of (A-11) at $p=p^{b}$ and $x_{i}=\chi\left(q^{b}\right)$. The resulting expression is

$$
\begin{aligned}
& \left(p_{i}-c\left(\chi\left(q^{b}\right)\right)\right) \partial_{p_{i}} q^{b}+q^{b}+\frac{\lambda}{2} \frac{d G\left(\chi\left(q^{b}\right), \chi\left(q^{b}\right)\right)}{d p_{i}}-\left(c^{\prime}\left(\chi\left(q^{b}\right)\right) q^{b}+F^{\prime}\left(\chi\left(q^{b}\right)\right)\right) \chi^{\prime}\left(q^{b}\right) \partial_{p_{i}} q^{b} \\
= & \frac{\lambda}{2} \frac{d G\left(\chi\left(q^{b}\right), \chi\left(q^{b}\right)\right)}{d p_{i}} \leq 0 \quad \forall \lambda \geq 0,
\end{aligned}
$$

where the equality holds by the envelope theorem, and the final inequality follows from

$$
\frac{d G\left(\chi\left(q^{b}\right), \chi\left(q^{b}\right)\right)}{d p_{i}}=\partial_{\chi} G\left(\chi\left(q^{b} \mid \lambda\right), \chi\left(q^{b} \mid \lambda\right)\right) \partial_{q_{i}} \chi\left(q^{b} \mid \lambda\right)\left(\partial_{p_{i}} q^{b}+\partial_{p_{k}} q^{b}\right)<0,
$$

which holds true in a symmetric equilibrium by the property that own price effects dominate cross price effects.

This shows that the price of a firm in the NSA is lower than in the benchmark. Since, by symmetry, this is true for both firms, the final quantities produced under the NSA are larger, and so are the values of firms' investments.

Let $n \geq 3$. We then resort to the aggregative formulation of the game. After dropping the functional notation for $q_{i}$, the maximization problem of a NSA insider is

$$
\max _{a_{i}}\left(\psi^{-1}\left(a_{i}\right)-c\left(\chi\left(q_{i} \mid \lambda\right)\right)\right) q_{i}-F\left(\chi\left(q_{i} \mid \lambda\right)\right)+\frac{\lambda}{2} G\left(\chi\left(q_{i} \mid \lambda\right), \chi\left(q_{k} \mid \lambda\right)\right) .
$$

The ensuing FOC with respect to $a_{i}$ is

$$
\begin{aligned}
& \left(\psi^{-1}\right)^{\prime}\left(a_{i}\right) q_{i}+\left(\psi^{-1}\left(a_{i}\right)-c\left(\chi\left(q_{i} \mid \lambda\right)\right)\right) \frac{d q_{i}}{d a_{i}} \\
& \quad-\left(c^{\prime}\left(\chi\left(q_{i} \mid \lambda\right)\right) q_{i}+F^{\prime}\left(\chi\left(q_{i} \mid \lambda\right)\right)\right) \chi^{\prime}\left(q_{i} \mid \lambda\right) \frac{d q_{i}}{d a_{i}}+\frac{\lambda}{2} \frac{d G\left(\chi\left(q_{i} \mid \lambda\right), \chi\left(q_{k} \mid \lambda\right)\right)}{d a_{i}}=0 .(A-1)
\end{aligned}
$$


Evaluating (A-12) at $a_{i}^{b}$, and invoking symmetry, yields

$$
\frac{\lambda}{2} \frac{d G\left(\chi\left(q^{b} \mid \lambda\right), \chi\left(q^{b} \mid \lambda\right)\right)}{d a_{i}}=\frac{\lambda}{2}\left(\frac{d q_{i}}{d a_{i}}+\frac{d q_{k}}{d a_{i}}\right) \partial_{\chi} G\left(\chi\left(q^{b} \mid \lambda\right), \chi\left(q^{b} \mid \lambda\right)\right) \chi^{\prime}\left(q^{b} \mid \lambda\right) \geq 0
$$

for all $\lambda \geq 0$, where $q^{b}$ is the quantity of an insider firm at $a^{b}$ and $A^{b}{ }^{55}$ Hence, NSA insiders will have an incentive to increase $a_{i}$ relative to the benchmark equilibrium, which will also result in an increase in the aggregate $A$.

Q.E.D.

${ }^{55}$ The FOC in the benchmark under the aggregative formulation is given by

$$
\left(\psi^{-1}\right)^{\prime}\left(a_{i}\right) q_{i}+\left(\psi^{-1}\left(a_{i}\right)-c\left(\chi\left(q_{i} \mid \lambda\right)\right)\right) \frac{d q_{i}}{d a_{i}}=0 .
$$




\section{References}

[1] Aghion, P., Bloom, N., Blundell, R., Griffith, R., and P. Howitt, 2005. Competition and Innovation: an Inverted-U Relationship. Quarterly Journal of Economics, 120(2), 701-728.

[2] Anderson, S. P., Erkal, N., and Piccinin, D., 2016. Aggregate Oligopoly Games with Entry. Mimeo.

[3] Anderson, S. P., Peitz, M., 2015. Media See-saws: Winners and Losers on Media Platforms. Mimeo.

[4] d'Aspremont, C., and Jacquemin, A., 1988. Cooperative and Noncooperative R\&D in Duopoly with Spillovers. American Economic Review 78, 1133-1137.

[5] Bartelsman, E., and Doms, M., 2000. Understanding Productivity: Lessons from Longitudinal Microdata. Journal of Economic Literature, 38, 569-94.

[6] Cornes, R., and Hartley, R., 2012. Fully Aggregative Games. Economics Letters, 116(3), 631-633.

[7] Deneckere, R., and Davidson, C., 1985. Incentives to Form Coalitions with Bertrand Competition. Rand Journal of Economics, 16(4), 473-486.

[8] Ericson, R., and Pakes, A., 1995. Markov-perfect Industry Dynamics: A Framework for Empirical Work. Review of Economic Studies, 62, 53-82.

[9] Faccio, M., and L. Zingales., 2017. Political Determinants of Competition in the Mobile Telecommunication Industry. NBER Working Paper No. 23041.

[10] Farrell, J., and Katz, M. L., 2006. The Economics of Welfare Standards in Antitrust, Competition Policy International, 2, 3-28.

[11] Farrell, J., and Shapiro, C., 1990. Horizontal Mergers: An Equilibrium Analysis. American Economic Review, 80(1), 107-126.

[12] Fershtman, C., and Pakes, A., 2000. A Dynamic Oligopoly with Collusion and Price Wars. Rand Journal of Economics, 31, 207-236.

[13] Focarelli, D., and Panetta, F., 2003. Are Mergers Beneficial to Consumers? Evidence from the Market for Bank Deposits. American Economic Review, 93(4), 1152-1172.

[14] Frontier Economics, 2014. European Mobile Network Operator Mergers. A Regulatory Assessment. Report commissioned by the GSM Association.

[15] Genakos, C., Valletti, T., and Verboven, F., 2016. Evaluating Market Consolidation in Mobile Communications. Mimeo.

[16] Gilbert, R., 2006. Looking for Mr. Schumpeter: Where are we in the Competitioninnovation Debate?, in Innovation Policy and the Economy (A. B. Jaffe, J. Lerner and S. Stern (eds)). The MIT Press. 
[17] Gowrisankaran, G., 1999. A Dynamic Model of Endogenous Horizontal Mergers. Rand Journal of Economics, 30, 56-83.

[18] Häckner, J., 2000. A Note on Price and Quantity Competition in Differentiated Oligopolies. Journal of Economic Theory, 93, 233-239.

[19] Hefti, A., forthcoming. Equilibria in Symmetric Games: Theory and Applications. Theoretical Economics.

[20] Jensen, M., 2010. Aggregative Games and Best-Reply Potentials. Economic Theory, 43(1), 45-66.

[21] Kolstad, C., and Mathiesen, L., 1987. Necessary and Sufficient Conditions for a Cournot Equilibrium. Review of Economic Studies, 54, 681-690.

[22] Lopez, A. L., and Vives, X., 2016. Cross-ownership, R\&D Spillovers and Antitrust Policy. Mimeo.

[23] Marshall, G., Parra, A., 2017. Mergers in Innovative Industries: The Role of Product Market Competition. Mimeo.

[24] Mermelstein, B., Nocke, V., Satterthwaite, M. A., and Whinston, M. D., 2015. Internal versus External Growth in Industries with Scale Economies: A Computational Model of Optimal Merger. Mimeo.

[25] Motta, M., 2004, Competition Policy. Theory and Practice. Cambridge University Press.

[26] Neven, D. J., and L.-H. Röller, 2005. Consumer Surplus vs. Welfare Standard in a Political Economy Model of Merger Control, International Journal of Industrial Organization, 23, 829-848.

[27] Nocke, V., and Schutz, N., 2016. Multiproduct-Firm Oligopoly: An Aggregative Games Approach. Mimeo.

[28] Nocke, V., and Whinston, M. D., 2010. Dynamic Merger Review. Journal of Political Economy, 118, 1200-51.

[29] Ornaghi, C., 2009. Mergers and Innovation in Big Pharma. International Journal of Industrial Organization, 27(1), 70-79.

[30] Pittman, R., 2007. Consumer Surplus as the Appropriate Standard for Antitrust Enforcement. Economic Analysis Group D.P. 07-9, Washington: Department of Justice.

[31] Salant, S. W., Switzer, S., and Reynolds, R. J., 1983. Losses from Horizontal Merger: The Effects of an Exogenous Change in Industry Structure on Cournot-Nash Equilibrium. Quarterly Journal of Economics, 98(2), 185-199.

[32] Schmutzler, A., 2013. Competition and Investment - A Unified Approach. International Journal of Industrial Organization, 31(5), 477-487. 
[33] Selten, R., 1970. Preispolitik der Mehrproduktenunternehmung in der Statischen Theorie. Springer Verlag.

[34] Shapiro, C., 2013. Competition and Innovation: Did Arrow Hit the Bull's Eye? in The Rate and Direction of Inventive Activity Revisited (J. Lerner and S. Stern (eds)). The MIT Press.

[35] Symeonidis, G., 2003. Comparing Bertrand and Cournot Equilibria in a Differentiated Duopoly with Product R\&D. International Journal of Industrial Organization, 21(1), 3955.

[36] Syverson, C., 2004. Market Structure and Productivity: A Concrete Example. Journal of Political Economy, 112, 1181-222.

[37] Vives, X., 1999. Oligopoly Pricing: Old Ideas and New Tools. MIT Press.

[38] Vives, X., 2008. Innovation and Competitive Pressure. Journal of Industrial Economics, 56(3), 419-469. 